\title{
Self-management interventions for adolescents living with HIV: a systematic review
}

Talitha Crowley ${ }^{1 *}$ and Anke Rohwer ${ }^{2}$

\begin{abstract}
Background: Self-management interventions aim to enable people living with chronic conditions to increase control over their condition in order to achieve optimal health and may be pertinent for young people with chronic illnesses such as HIV. Our aim was to evaluate the effectiveness of self-management interventions for improving health-related outcomes of adolescents living with HIV (ALHIV) and identify the components that are most effective, particularly in low-resource settings with a high HIV burden.

Methods: We considered randomised controlled trials (RCTs), cluster RCTs, non-randomised controlled trials (nonRCTs) and controlled before-after (CBA) studies. We did a comprehensive search up to 1 August 2019. Two authors independently screened titles, abstracts and full texts, extracted data and assessed the risk of bias. We synthesised results in a meta-analysis where studies were sufficiently homogenous. In case of substantial heterogeneity, we synthesised results narratively. We assessed the certainty of evidence using GRADE and presented our findings as summaries in tabulated form.
\end{abstract}

Results: We included 14 studies, comprising 12 RCTs and two non-RCTs. Most studies were conducted in the United States, one in Thailand and four in Africa. Interventions were diverse, addressing a variety of selfmanagement domains and including a combination of individual, group, face-to-face, cell phone or information communication technology mediated approaches. Delivery agents varied from trained counsellors to healthcare workers and peers. Self-management interventions compared to usual care for ALHIV made little to no difference to most health-related outcomes, but the evidence is very uncertain. Self-management interventions may increase adherence and decrease HIV viral load, but the evidence is very uncertain. We could not identify any particular components of interventions that were more effective for improving certain outcomes.

Conclusion: Existing evidence on the effectiveness of self-management interventions for improving health-related outcomes of ALHIV is very uncertain. Self-management interventions for ALHIV should take into account the individual, social and health system contexts. Intervention components need to be aligned to the desired outcomes.

Systematic review registration: PROSPERO CRD42019126313.

Keywords: Self-management, HIV/AIDS, Adolescents, Systematic review, Protocol

\footnotetext{
* Correspondence: tcrowley@sun.ac.za

'Department of Nursing and Midwifery, Faculty of Medicine and Health

Sciences, Stellenbosch University, Cape Town, South Africa

Full list of author information is available at the end of the article
}

(c) The Author(s). 2021 Open Access This article is licensed under a Creative Commons Attribution 4.0 International License, which permits use, sharing, adaptation, distribution and reproduction in any medium or format, as long as you give appropriate credit to the original author(s) and the source, provide a link to the Creative Commons licence, and indicate if changes were made. The images or other third party material in this article are included in the article's Creative Commons licence, unless indicated otherwise in a credit line to the material. If material is not included in the article's Creative Commons licence and your intended use is not permitted by statutory regulation or exceeds the permitted use, you will need to obtain permission directly from the copyright holder. To view a copy of this licence, visit http://creativecommons.org/licenses/by/4.0/ The Creative Commons Public Domain Dedication waiver (http://creativecommons.org/publicdomain/zero/1.0/) applies to the data made available in this article, unless otherwise stated in a credit line to the data. 


\section{Background}

HIV affects 1,740,000 adolescents between the ages of 10 and 19 globally with the highest burden in subSaharan Africa [1]. Adolescence is a developmental stage that includes many physical, cognitive and social changes that may be adversely affected by living with a chronic illness [2, 3]. Adolescents living with HIV (ALHIV) may have acquired HIV perinatally, through mother-to-childtransmission or behaviourally through, for example, sexual transmission [4]. Although effective prevention of mother-to-child-transmission strategies have led to fewer children acquiring HIV perinatally, new HIV infections continue to rise amongst adolescents, with 170,000 new infections occurring in 2019 [1]. Globally, adolescent treatment outcomes are poor compared to those of adults, while AIDS is the leading cause of death amongst adolescents in Africa [5].

ALHIV are faced with the dual challenge of having to live with a life-long chronic condition and adhere to treatment, while being confronted with developmental challenges and HIV-related stigma [6]. Supporting them through this vulnerable phase to ensure they make a safe and productive transition to adulthood requires a differentiated care approach - a type of patient-centred approach where HIV care and services are adapted to suit the needs of certain groups [7]. One such approach is self-management support. Self-management has been defined as the "day to day management of chronic conditions by individuals over the course of an illness" [8] (p e26). Self-management support may be particularly important for adolescents, as they can gain skills for lifelong management of their chronic illness. Furthermore, the participative approach to care is likely to appeal to them [9].

Different theories and frameworks to describe the concept of self-management exist. However, key similarities include a focus on the development of self-management abilities and behaviours to manage a chronic condition and achieve health-related outcomes [10-13]. Table 1 illustrates the self-management abilities and selfmanagement behaviours described in the various general chronic disease and HIV-specific self-management theories or frameworks. Self-management interventions usually focus on improving self-management abilities as these are the most amenable to change, empowering people living with a chronic condition to increase control over their condition to achieve optimal health [11].

For the purpose of this review, we chose to focus on interventions that 1) increase ALHIV's knowledge and beliefs about their disease; 2) improve self-regulation skills and abilities; and 3) assist ALHIV to utilise resources, also referred to as social facilitation. These selfmanagement domains are described in the Individual and Family Self-Management Theory (IFSMT) [16] and provide a framework to classify interventions. The IFSM $T$ integrates a socio-ecological approach with cognitive theory and takes the individual, social and physical environment into account when explaining self-management [11]. Processing skills, including self-efficacy and knowledge, self-regulation (goal-setting, self-monitoring, emotionalcontrol, etc.), and social facilitation are interrelated processes that are needed to implement self-management behaviours (e.g. taking treatment and attending appointments) [11]. The self-management domains described in the IFSMT have been associated with better adherence, health-related quality of life and viral suppression amongst ALHIV [21]. The assumption is that addressing multiple self-management domains will lead to a larger effect on behavioural and health outcomes.

Self-management interventions may differ slightly based on the context and the individual needs of the target group [15, 22]. They may be focused on the adolescent or involve both the adolescent and family as selfmanagement takes place in the context of individual and environmental risk and protective factors [11, 16]. Furthermore, one can classify interventions based on the abilities they are targeting (Table 1).

Effects of self-management interventions on behavioural and health outcomes have been measured in various ways. In their scoping review on self-management interventions for people living with HIV, Bernardin, Toews, Restall and Vuangphan (2013) identified the following key outcomes: well-being and quality of life, health and illness management, and health services use [18]. Sattoe et al. (2015) developed a framework for selecting outcome measures for chronic disease self-management interventions according to whether the interventions target medical, emotional or role management [9]. These outcomes include, but are not limited to, disease knowledge, illness-related self-efficacy, problem-solving, social participation, psychosocial functioning, support by others, coping, and health-related quality of life [9]. A recent systematic review on interventions to improve self-management of adults living with HIV focused on the outcomes as outlined in the IFSMT, including physical health, psychosocial outcomes and behavioural outcomes [23].

We developed a logic model, informed by existing literature and author expertise using the IFSMT [16] as an organising framework (Fig. 1) to depict the components of self-management interventions (according to the selfmanagement domains), the pathway from the intervention to the outcomes, as well as how the intervention interacts with implementation and context variables. It thus helped us to unpack the complexity related to the intervention, the outcomes, and the contextual factors relevant to this review [24].

Although self-management interventions are a promising strategy for improving outcomes in adolescents 


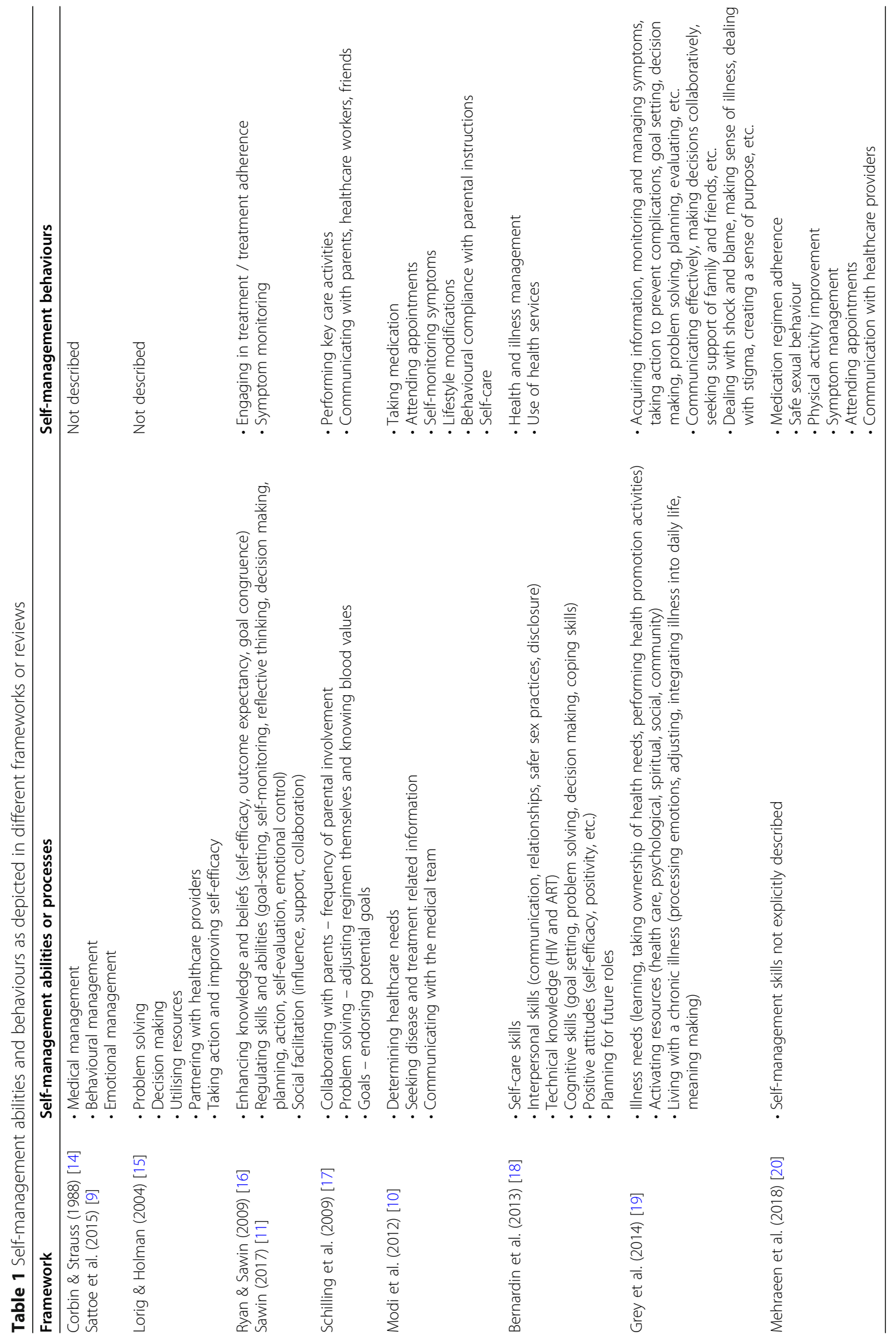




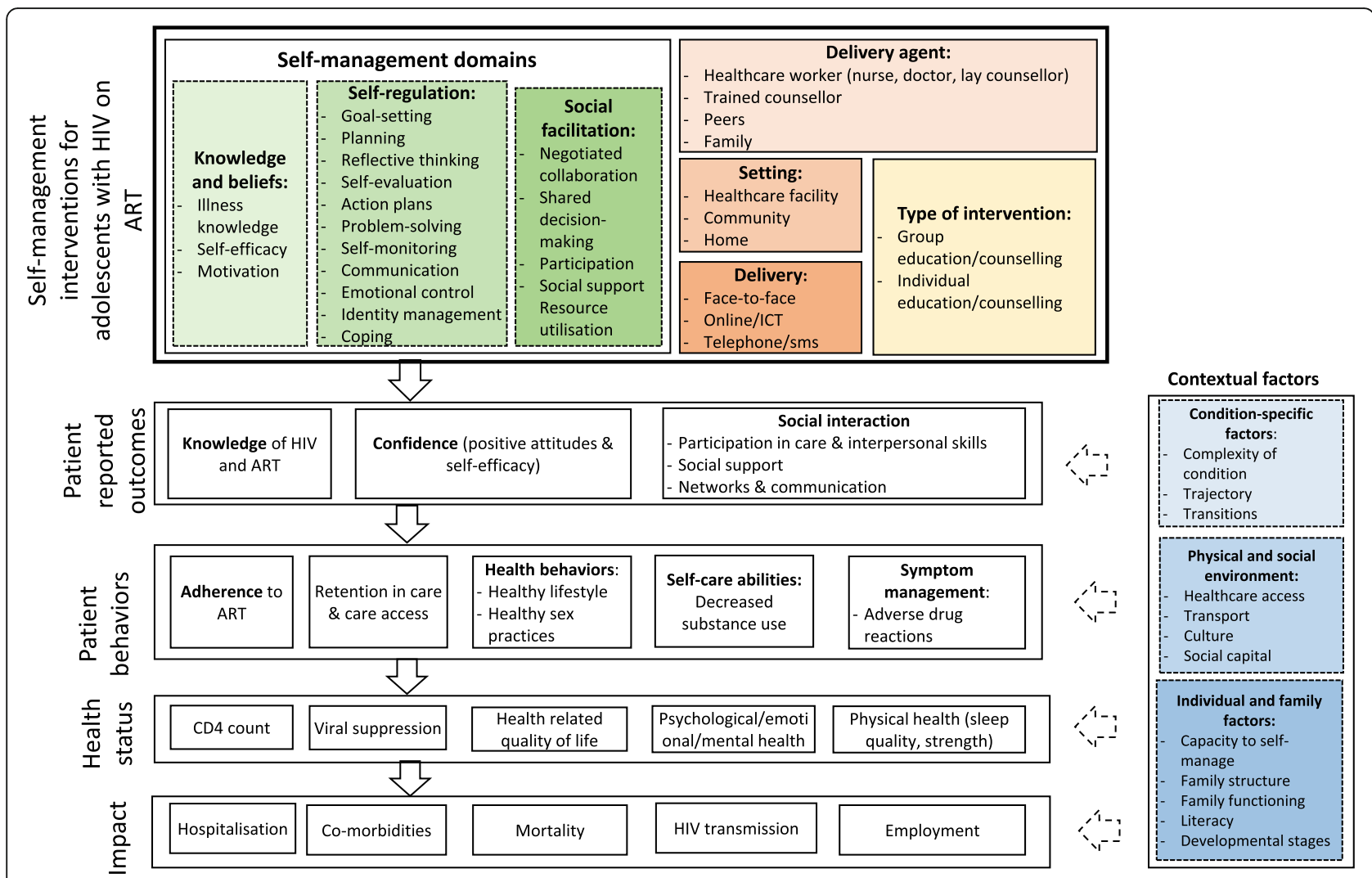

Fig. 1 Logic Model

living with chronic conditions, evidence of effectiveness is lacking. While existing systematic reviews have investigated the effects of self-management interventions on health outcomes, few have specifically focused on ALHIV in settings with scarce resources. Two reviews focused on young people with any chronic condition [9, $25]$, but not specifically on adolescents. Reviews that focused on HIV-specific self-management interventions [23, 26-29] included mostly adults or excluded studies conducted in Africa [26-30]. Furthermore, there is insufficient evidence of effective components of selfmanagement interventions to inform the development of interventions for ALHIV, particularly in low-resource settings and for interventions focusing on improving social support, managing risk behaviours, and enhancing quality of life $[9,18]$. Only one review identified components of self-management interventions that appear to improve specific outcomes across chronic conditions [25]. However, included studies were too heterogeneous to make confident conclusions about the effectiveness of various intervention components. It is, therefore, still not clear which self-management interventions could optimise the health outcomes of ALHIV. Due to their developmental phase, self-management interventions for this group may differ from that of adults [9].
The aim of this systematic review was to determine the effectiveness of self-management interventions to improve health-related outcomes of ALHIV and identify the intervention components that are the most effective, particularly in low-resource settings with a high HIV burden.

\section{Objectives}

The specific objectives were to:

- Assess the effectiveness of self-management interventions on improving health-related outcomes of ALHIV on ART.

- Describe various self-management interventions and their components.

- Determine which interventions may be relevant in low-resource settings with high HIV burden.

\section{Methods}

\section{Study design}

We conducted a systematic review of self-management interventions for ALHIV on ART and reported it according to the PRISMA reporting guidelines [31] (See Additional file 1). Our protocol was registered with the International Prospective Register of Systematic Reviews 
(PROSPERO) on 23 February 2019 (Reference no. CRD42019126313).

\section{Eligibility criteria}

Studies were eligible for inclusion if they met the following eligibility criteria:

\section{Types of studies}

We included randomised controlled trials (RCTs), cluster RCTs, non-randomised controlled trials (non-RCTs) and controlled before-after (CBA) studies. We only considered cluster RCTs and CBAs with at least two intervention and two control sites [32].

\section{Types of participants}

We included adolescents aged 10 to 19 , according to the definition of the World Health Organisation (WHO) [2], with a diagnosis of HIV and on ART. We also included studies on young people (10 to 24 years) to account for overlap in the definition of adolescents, young people and youth [33]. Interventions that targeted adolescents and family members as well as studies conducted in low-, middle- and high-income countries were included.

\section{Types of interventions}

A self-management intervention was defined as any educational strategy to encourage individuals to manage their disease [18]. For the purpose of this review, interventions had to have an educational component that addressed one or more of the following self-management domains as per our logic model (Fig. 1):

1) Knowledge and beliefs: illness knowledge, selfefficacy, motivation.

2) Self-regulation skills and abilities: goal setting, planning, reflective thinking, self-evaluation, action plans, problem-solving, self-monitoring, communication, emotional control, identity management.

3) Social facilitation/utilisation of resources: negotiated collaboration, shared decision-making and participation.

We did not consider interventions that focused on illness knowledge only. Although knowledge is necessary for self-efficacy, knowledge alone does not explain behaviour change [11].

We considered any type of educational intervention, including group education or counselling, and individual education or counselling delivered in any setting (healthcare facility, community, home) by any type of healthcare worker, peers or family members. We included both face-to-face and online information communication technology (ICT) delivery of interventions. Multi-faceted interventions that included components such as short- text-messaging (SMS) reminders or peer support were included if they had an educational component.

Types of comparisons: We considered the following comparisons:

1) Self-management interventions addressing one to two self-management domains versus control (no intervention, standard care, other interventions with no self-management component or wait list).

2) Self-management interventions addressing all three self-management domains versus control (no intervention, standard care, other interventions with no self-management component or wait list).

3) Self-management interventions versus other interventions with a different self-management component.

\section{Types of outcomes}

We included studies reporting on either primary or secondary outcomes. As per our logic model (Fig. 1), we considered the following groups of outcomes: Patientreported outcomes; behavioural outcomes; measures of health status; and impact outcomes. We included outcomes measured at any point in time following the intervention.

Primary outcomes (as defined by study authors)

1. Patient-reported outcomes: knowledge and understanding of illness (HIV and ART), confidence (positive attitude, self-efficacy, empowerment); motivation; perceived social support; participation in care; interpersonal skills; networks and communication.

2. Patient behaviours: adherence to medication; health/risk behaviours; self-care abilities (decreased substance use); symptom management (e.g. handling adverse effects of drugs).

3. Health status: viral suppression.

4. Health status: CD4 count

Secondary outcomes (as defined by study authors)

1. Health status: health-related quality of life; mental/ psychological health; emotional health; physical health.

2. Patient behaviours: clinic attendance/utilisation; retention in care.

3. Impact: Hospitalisation; co-morbidities; all-cause mortality; HIV transmission; employment.

\section{Information sources and search strategy}

An information specialist performed the search on the following electronic databases: MEDLINE PubMed, EMBASE (Ovid), CENTRAL (Cochrane), Africa-Wide 
(EBSCOhost), CINAHL (EBSCOhost), Web of Science Core Collection: SCI-EXPANDED, CPCI-S, SSCI (Clarivate Analytics), and LILACS (Virtual Health Library). We searched ClinicalTrials.gov (www.ClinicalTrials.gov) and the World Health Organisation (WHO) trials portal (www.who.int/ictrp/en/) to identify unpublished and ongoing studies. In addition, we searched grey literature such as university thesis/dissertation databases and conference abstracts, such as the International AIDS Conference and the Conference on Retroviruses and Opportunistic Infections (CROI). Databases were searched from their inception to 1 August 2019 and there was no restriction on language of publication. To complement the electronic search, we screened reference lists of included studies and relevant systematic reviews. Specialists in the field and authors of the included studies were contacted to identify additional unpublished studies.

We included search terms related to HIV/AIDS, ART, adolescents and self-management, their synonyms, and Medical Subject Headings (MeSH). Additional file 2 contains the full search strategy for all the databases.

\section{Selection of studies and data extraction}

Two review authors used Covidence software to independently screen titles and abstracts to identify potentially eligible studies. We obtained full texts of these studies and independently assessed them to determine eligibility. Disagreements were resolved through discussion. We classified studies as included, excluded with reasons, and ongoing. Authors of studies were contacted in case of missing information.

Two authors independently extracted data using a prespecified, pre-piloted data extraction form in Covidence. We extracted data on the study design, characteristics of participants, type and description of intervention, outcomes, setting and funding sources. We used a standardised form adapted from the 12-item Template for Intervention Description and Replication (TIDier) checklist [34] to describe components of self-management interventions. This assisted to record important aspects of the intervention such as the theoretical foundation, whether it was tailored for adolescents and the context, the person(s) delivering the intervention and their training, the setting, the specific self-management components addressed, materials used, and procedures followed. We resolved disagreements through discussion.

Two authors independently assessed the risk of bias according to the criteria outlined in the Cochrane Effective Practice and Organisation of Care (EPOC) guidelines [32]. For each study, we assessed the following domains as having high, low or unclear risk of bias: random sequence generation, allocation concealment, baseline outcome measurements, baseline characteristics, incomplete outcome data, blinding, protections against contamination, selective outcome reporting and other risks of bias. We resolved discrepancies through discussion.

\section{Data analysis and synthesis}

One author entered data extracted from individual studies into Review Manager (2014) for analysis and a second author checked the data entry. For dichotomous data, we reported risk ratios or odds ratios with $95 \%$ confidence intervals (CIs) to summarise effects. For continuous data, we reported mean differences (MDs) and $95 \%$ CIs where studies used the same scale to measure outcomes. To summarise effects, we reported standardised mean differences (SMDs) and 95\%CIs where studies used different scales to measure outcomes. We used adjusted measures where studies reported these.

In the case of missing data, we contacted study authors to obtain the data and sent reminders if no response was received. Where authors did not respond or did not provide the data requested, data were reported as missing. We did not impute any data.

We expected high levels of heterogeneity and explored clinical heterogeneity linked to the participants, intervention, setting, outcome measurement and study design, and described these study characteristics in table format. Statistical heterogeneity was assessed using $\mathrm{I}^{2}$, $\mathrm{Tau}^{2}$ and $\mathrm{Chi}^{2}$ statistics. We considered heterogeneity to be significant if $\mathrm{Tau}^{2}$ was more than one or if the $p$ value of the $\mathrm{Chi}^{2}$ test was less than 0.1. We considered an $\mathrm{I}^{2}$ statistic of more than $30 \%$ as substantial heterogeneity [35]. Since we did not have more than 10 studies in the meta-analyses, we were not able to explore reporting biases with funnel plots.

Statistical analyses were performed using Review Manager. We used fixed-effect meta-analysis to pool data that was sufficiently homogenous. Where we considered heterogeneity to be high, we did not pool data, but rather presented findings per study in a narrative synthesis. We used forest plots to report data for each outcome, showing either the pooled data for outcomes where meta-analysis was possible or data for each study where we did not pool data.

We had planned to conduct subgroup analysis on type of intervention, delivery agent, age groups and setting. We also planned to carry out sensitivity analyses on primary outcomes to examine the effect of studies with high risk of selection and attrition bias, to examine the effect of imputed data, and to examine the effect of studies that did not stratify results according to required age ranges for adolescents. However, since we only performed meta-analysis for a few outcomes and included few studies, we did not perform subgroup or sensitivity analyses. 


\section{Certainty of the evidence}

We assessed the certainty of evidence using GRADE (Grades of Recommendation, Assessment, Development and Evaluation) [36] for the following outcomes: confidence, adherence, risk behaviour, viral load, and mental health (depression). We assessed study limitations, consistency of effect, imprecision, indirectness and publication bias when we considered downgrading the certainty of evidence $[37,38]$. For each outcome, we described the certainty of evidence to be very low, low, moderate or high. We used GRADEPro software [39] to generate summaries of the findings in tabulated format.

\section{Ethical considerations}

The systematic review formed part of a larger study with the aim to develop a self-management intervention for ALHIV. This larger study received Health Research Ethics Approval from Stellenbosch University, South Africa (N18/06/064).

\section{Results}

We screened titles and abstracts of 2305 studies, and full texts of 47 potentially relevant studies (see Fig. 2). We included 25 studies in this review of which 14 were completed and 11 were ongoing studies (Additional file 3). We excluded 21 studies with reasons provided in Additional file 4.

\section{Characteristics of included studies}

The characteristics of included studies are summarised in Table 2 . The majority of studies $(n=9)$ were conducted in the USA, one in Thailand and four in Africa. Settings varied from health facilities to communities in urban and rural areas, and home settings via ICT, phone and gaming platforms. Two studies $[47,50]$ were nonRCTs, while the rest were RCTs with total sample size varying between $n=14$ and $n=356$. Most studies included adolescents and youth of various age groups, with one study [47] focusing on younger children aged 5 to 14. Six of the 14 interventions targeted adolescents or youth with poor adherence or risk behaviours [40, 47, $50,51,53,56]$. Studies included both male and female participants, although five studies $[48,49,54-56]$ had predominantly male participants $(>75 \%)$. One study, the Vuka Family Programme, included both adolescents and parents [42], and one study (Multisystemic Therapy) included families [50]. Most interventions targeted adolescents on ART, irrespective of the mode of infection (perinatally or behaviourally).

Primary outcomes were mostly health status outcomes such as viral suppression $(n=9)$ or behaviour outcomes such as adherence $(n=12)$. Seven studies also included mental health as an outcome. No studies assessed impact.

\section{Summary of interventions}

Details of the included interventions are summarised in Tables 3 and 4 . Interventions were mostly health facility

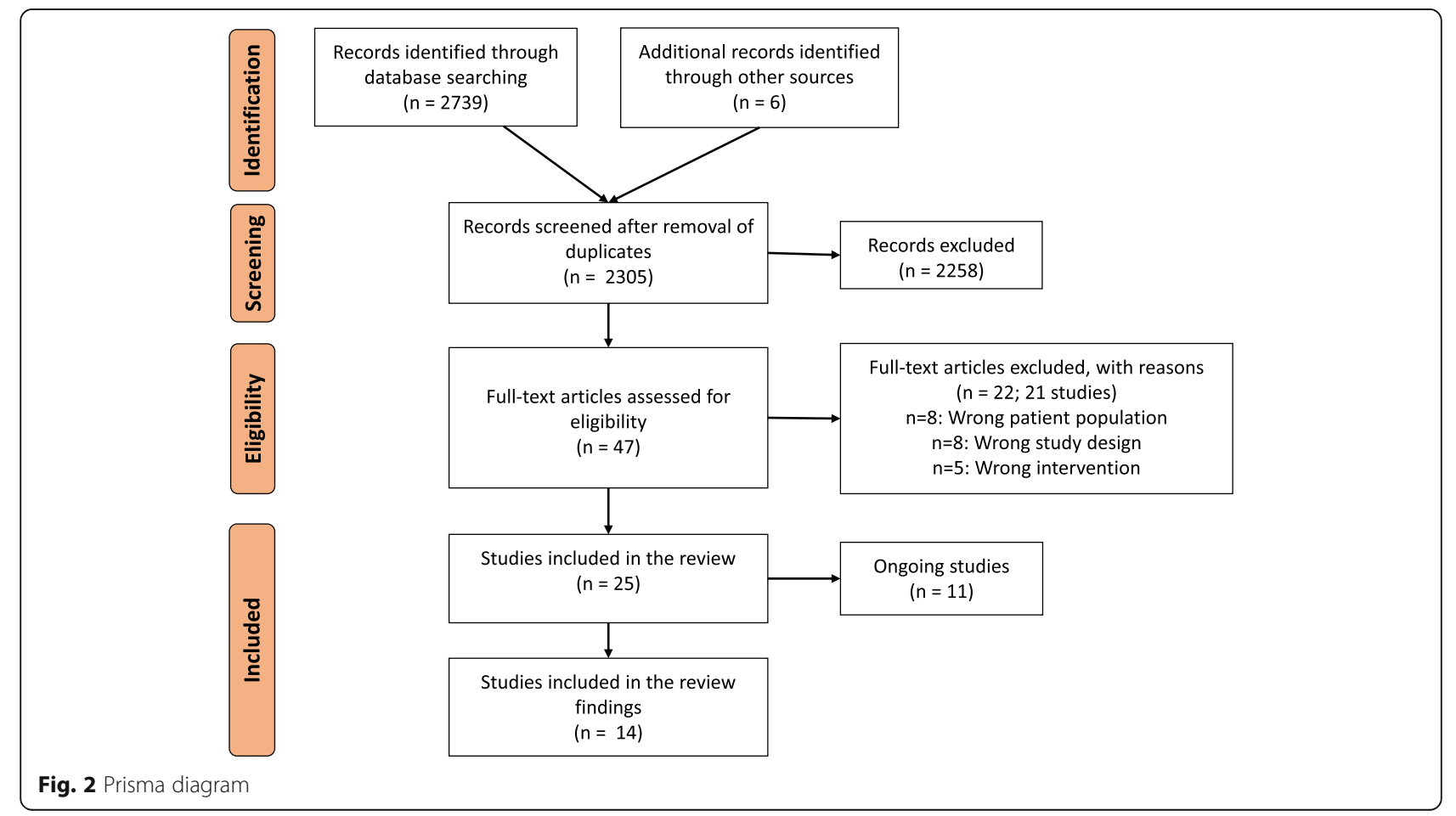




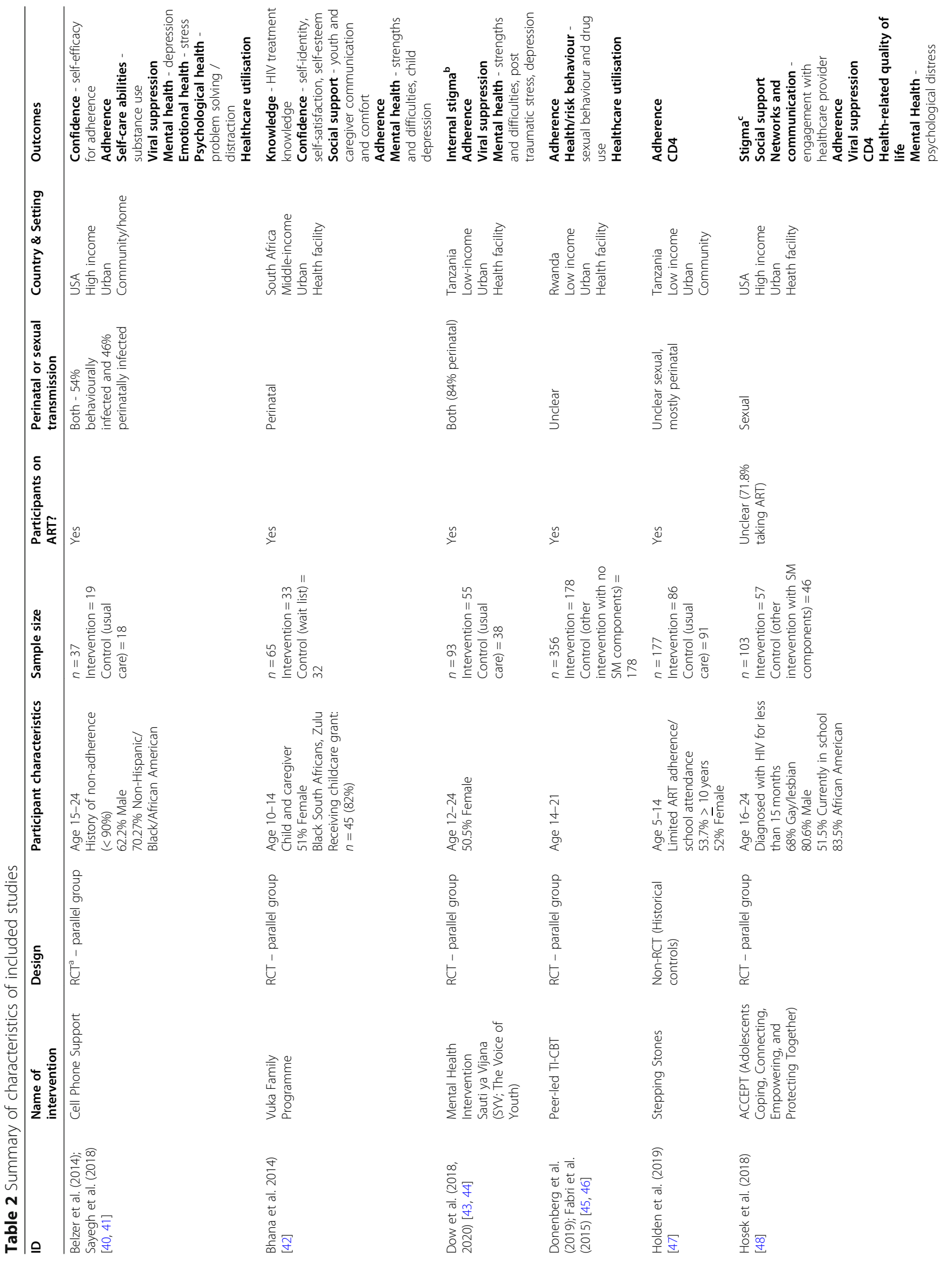




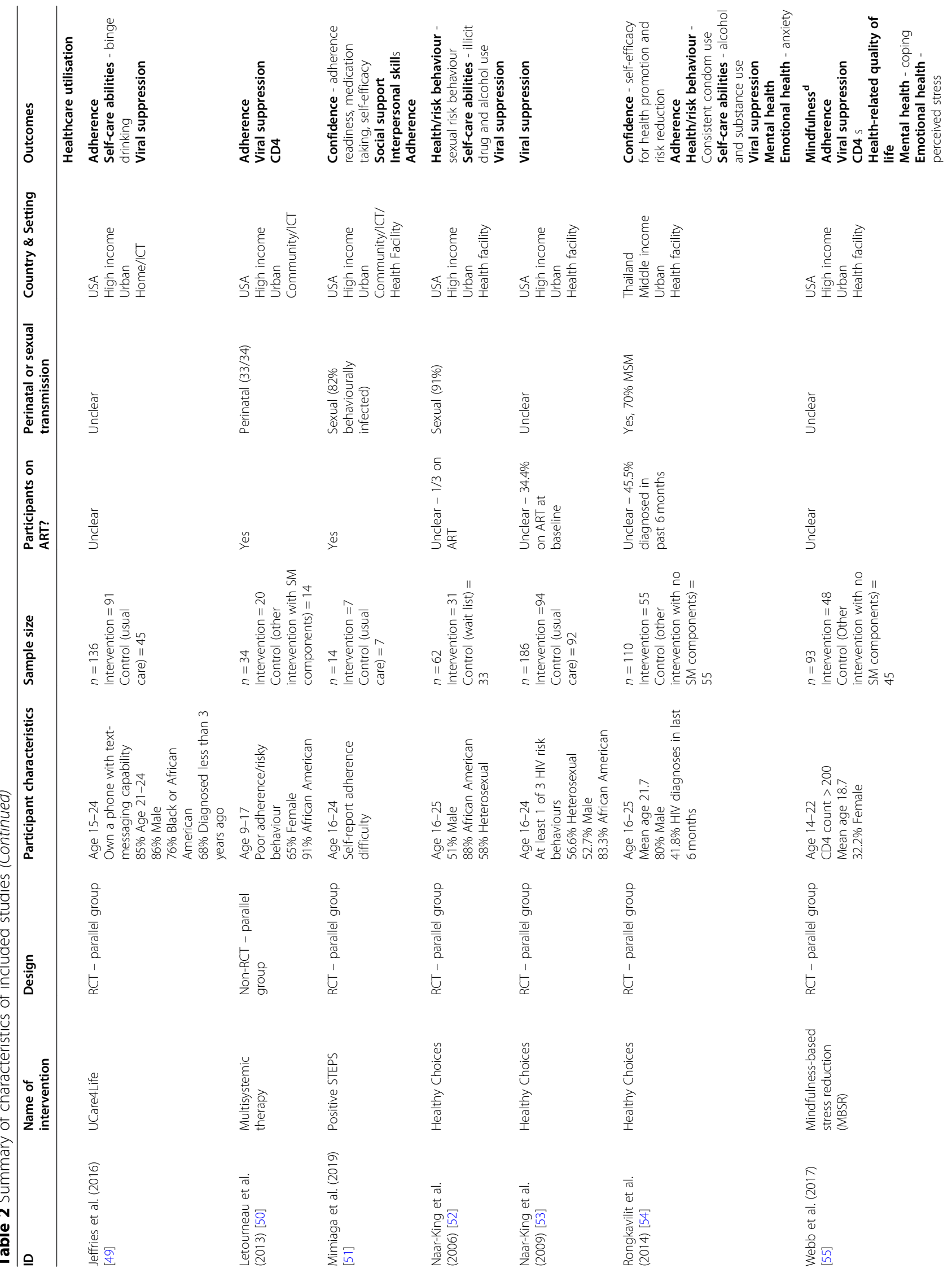




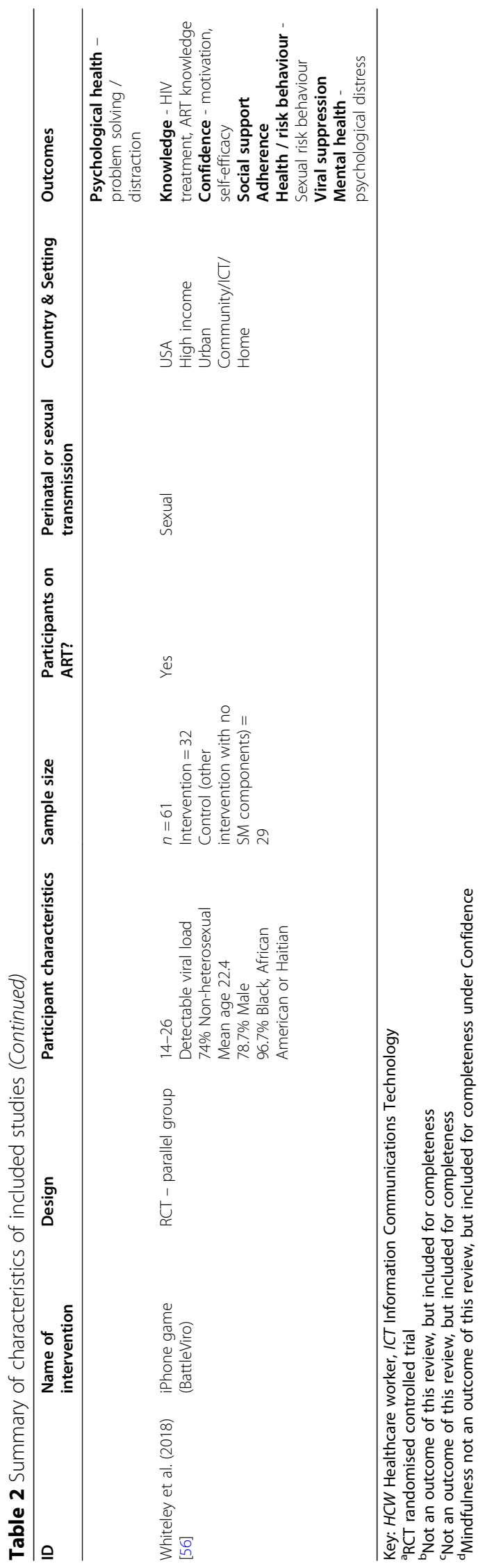




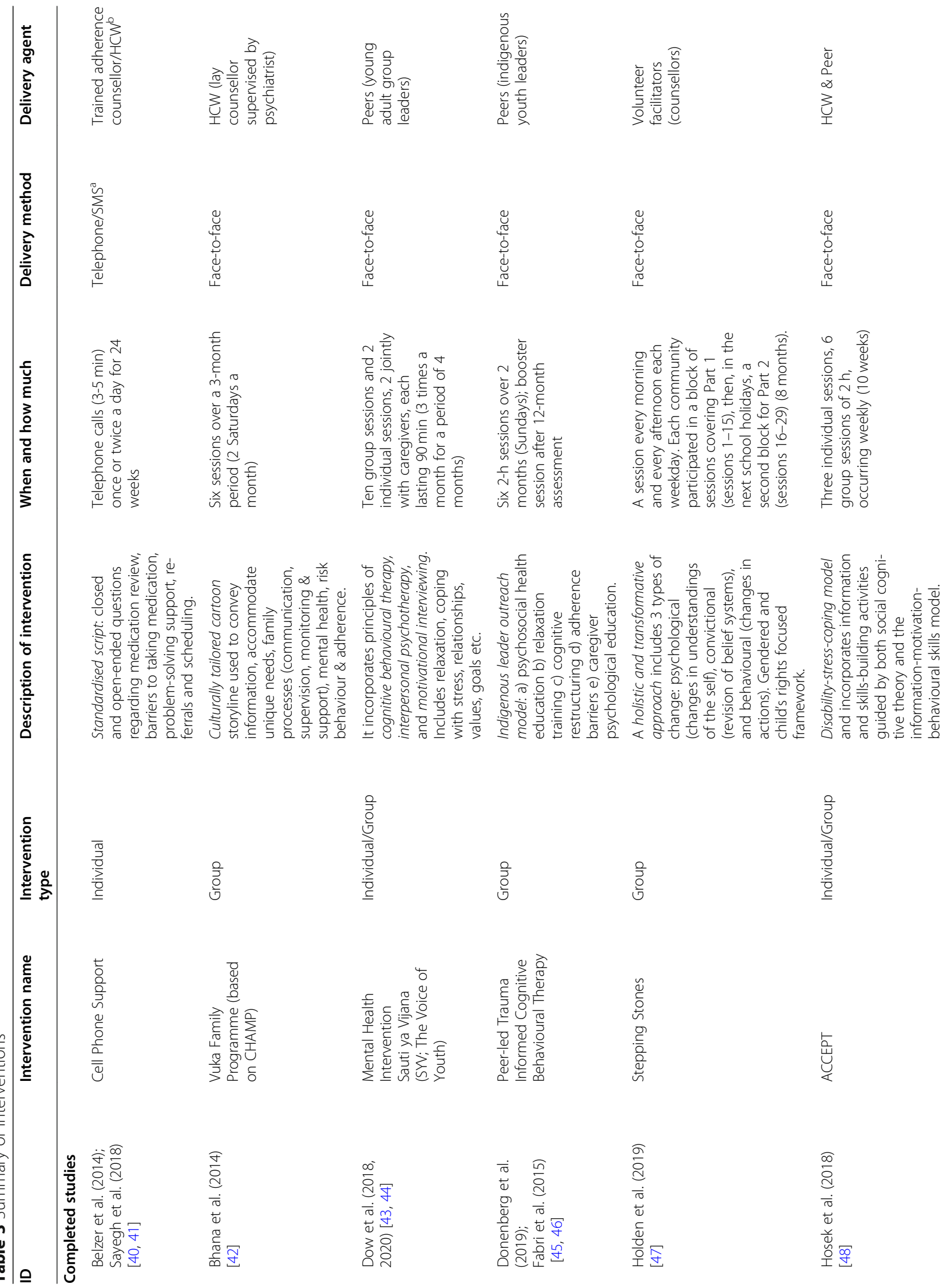




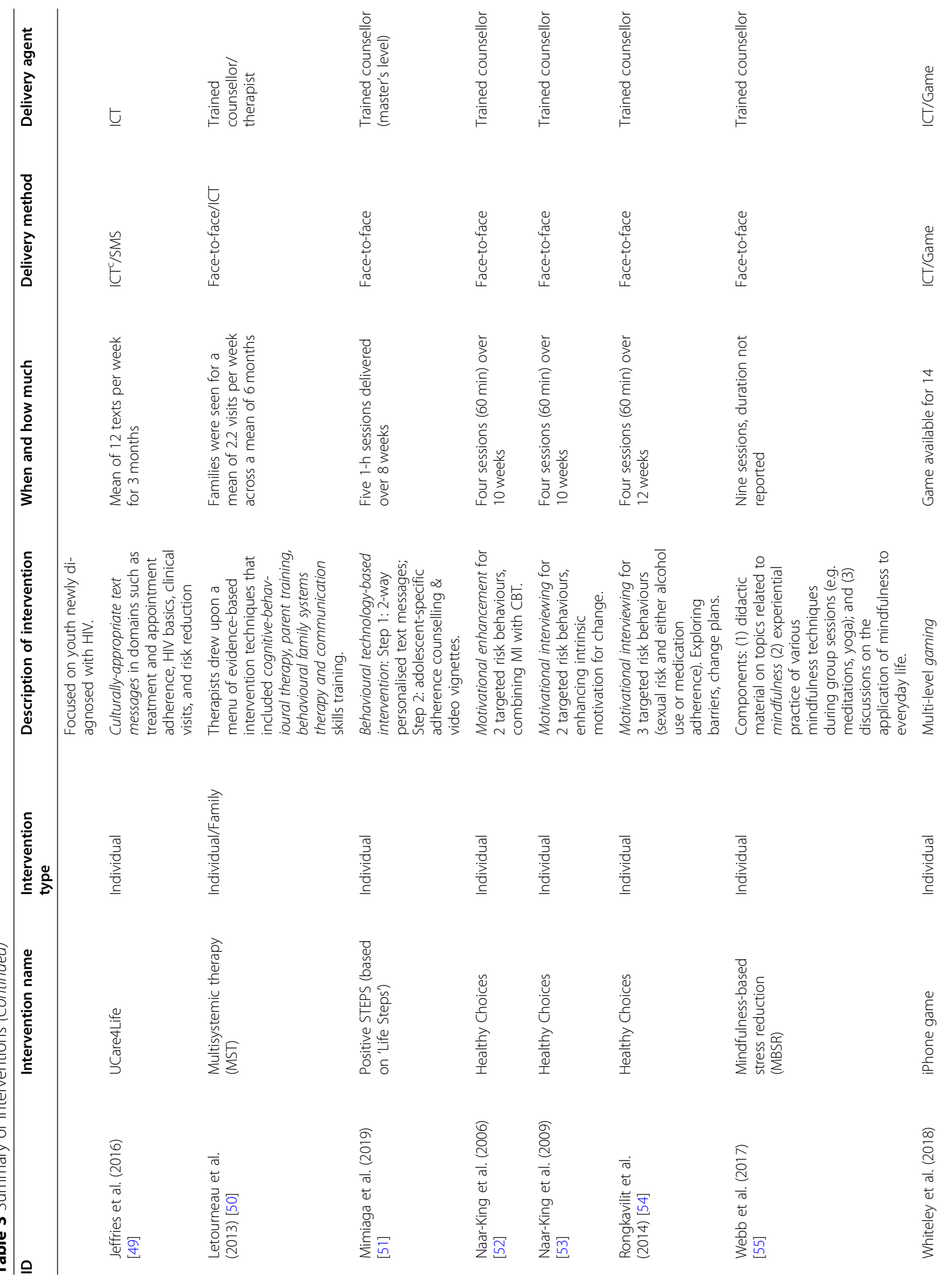




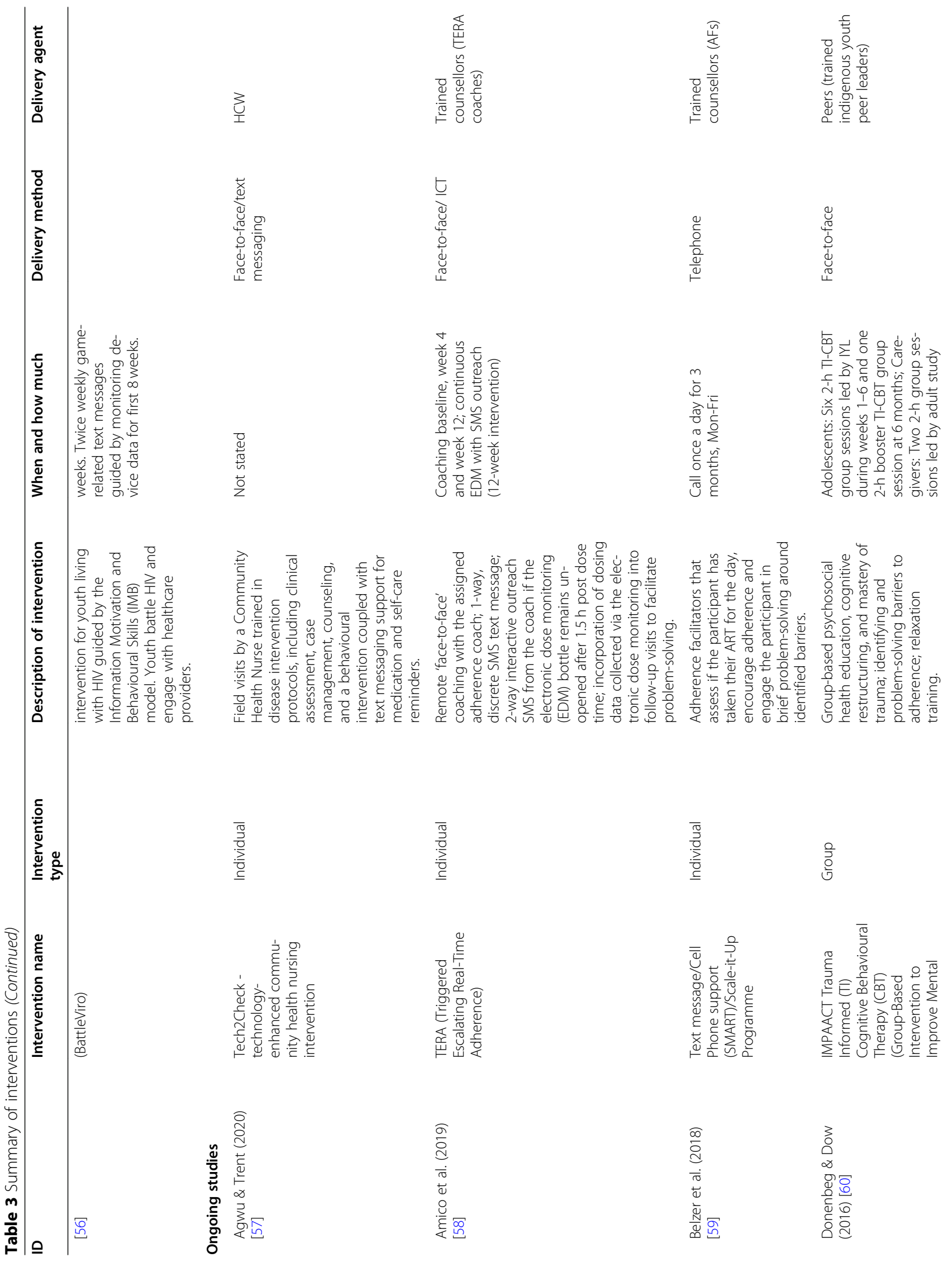




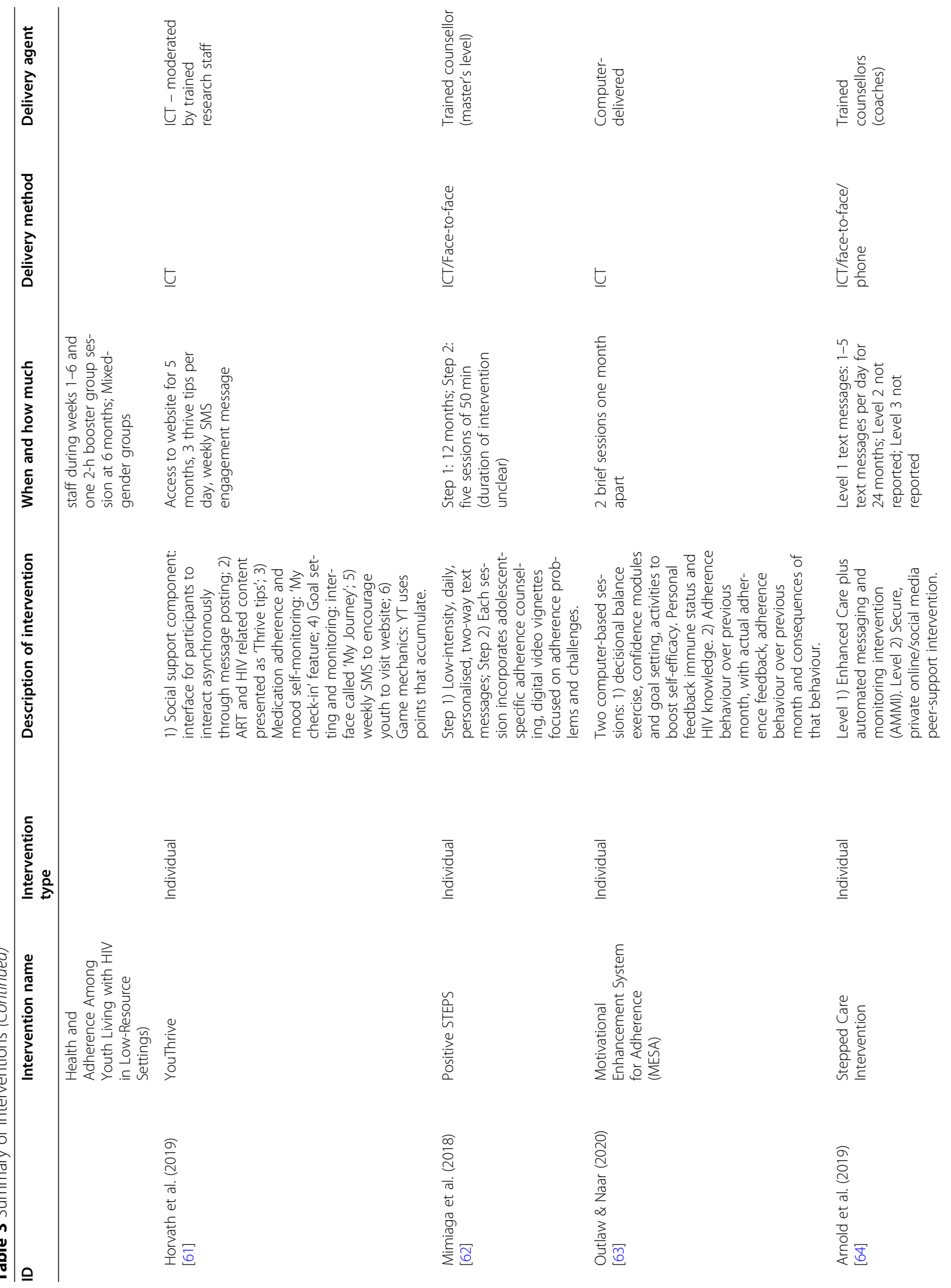




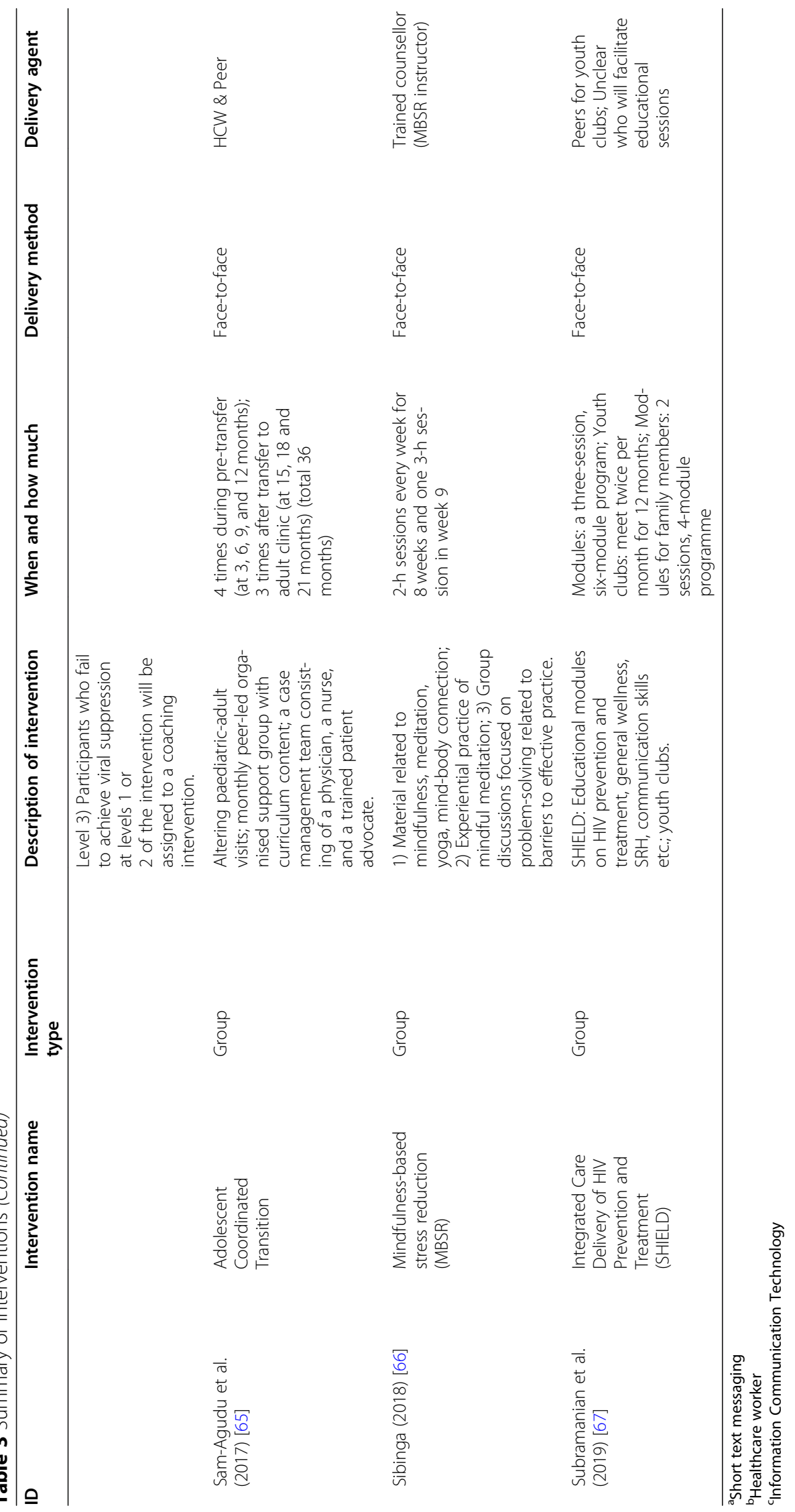




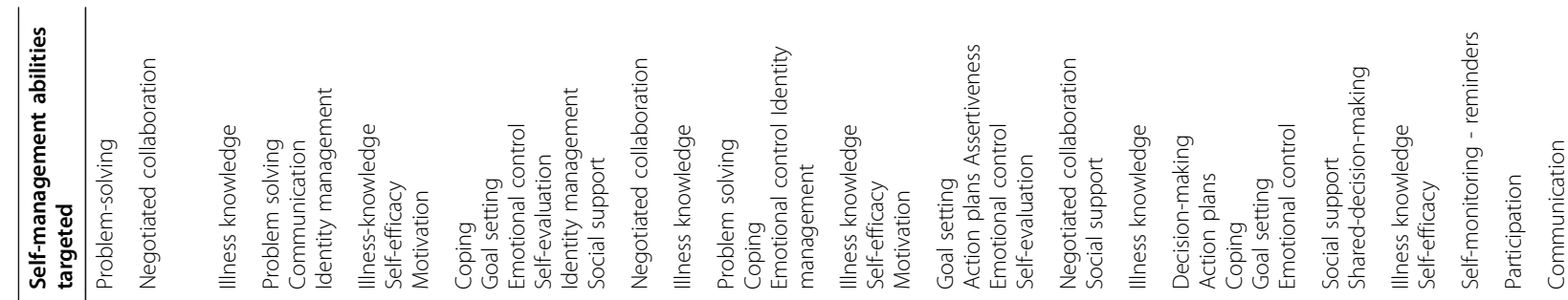
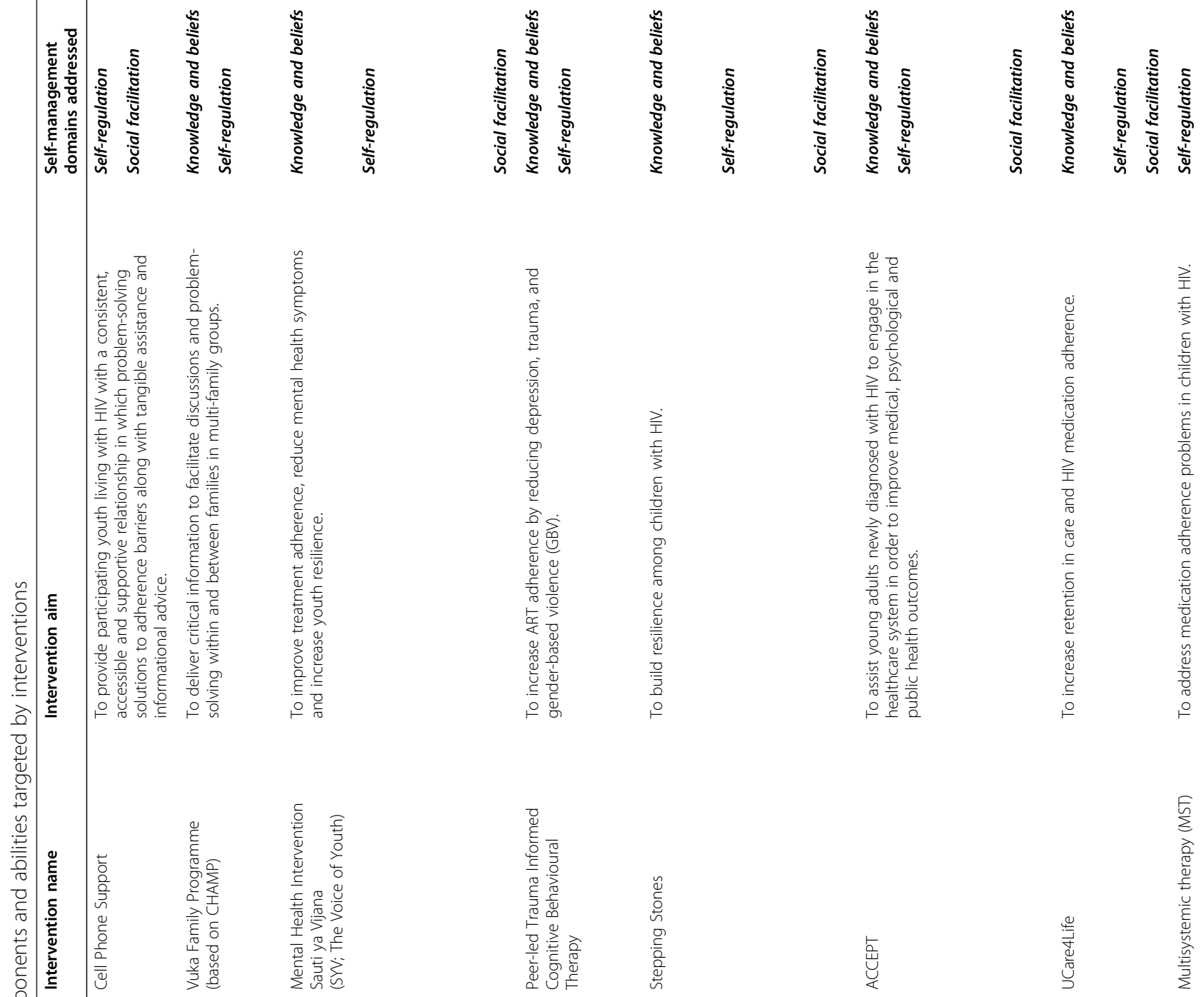

点
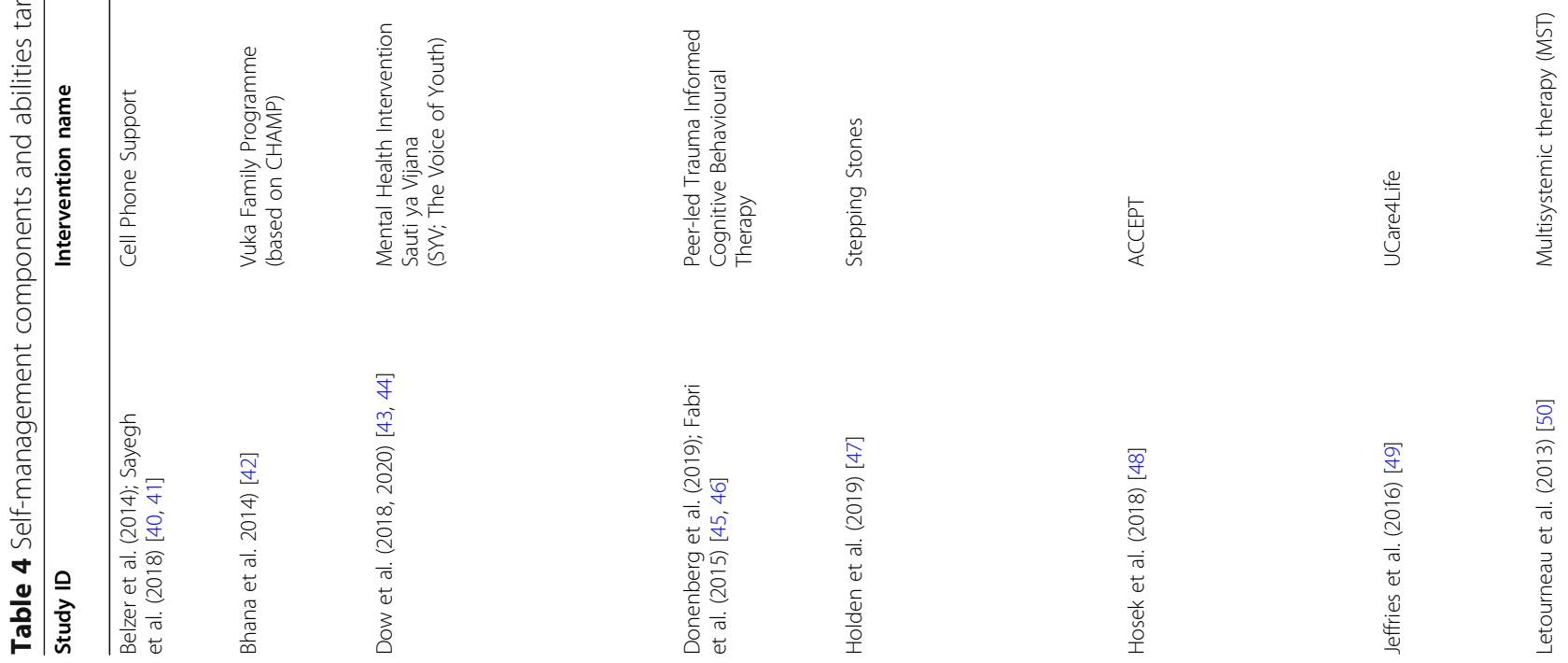


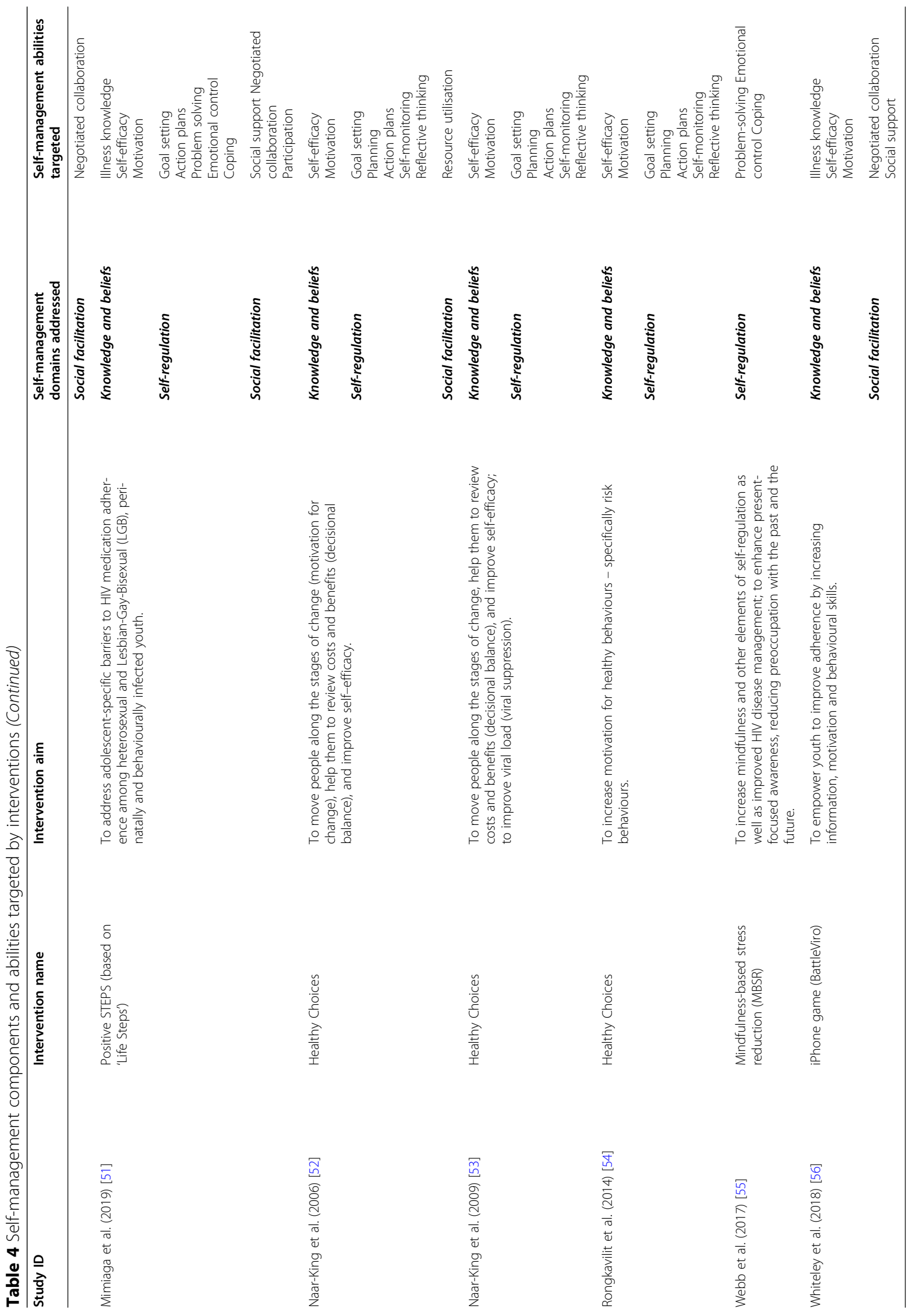


based $(n=9)$ and delivered either completely face-toface $(n=10)$ or had a face-to-face component $(n=1)$. Four interventions used platforms such as ICT, telephone, SMS or gaming. Interventions varied from cell phone support, culturally tailored text messages, indigenous leader outreach models, multisystemic therapy, cognitive behavioural therapy, motivational interviewing and mindfulness. Some interventions were brief (4 sessions over 2 months) while one intervention, Stepping Stones, comprised up to 29 sessions over a period of 8 months [47]. Three studies used the same intervention, Healthy Choices, as a pilot and larger study in the USA that was later adapted for Thailand [52-54]. Half of the interventions used trained counsellors to deliver the intervention. Six interventions addressed all three selfmanagement domains and only one intervention addressed one domain. The domain most often targeted, was self-regulation, followed by knowledge and beliefs. Table 4 provides an overview of the domains and specific abilities targeted in the completed studies. The abilities the most often targeted were: illness knowledge (8 studies), self-efficacy (8 studies), motivation (7 studies), goalsetting (7 studies), action plans (6 studies), emotional control (6 studies), and negotiated collaboration (6 studies).

The theories mostly used to develop the interventions included social influence theories such as Social Cognitive Theory, Cognitive Behaviour Theory (CBT), Ecological Systems Theory and Information, and Motivation and Behaviour Skills (IMBS).

In Africa, the four completed studies as well as the ongoing studies used predominantly group education and counselling delivered by lay workers or peers with no ICT/phone interventions.

\section{Risk of bias of included studies}

Overall, risk of bias across domains was moderate to high across studies and is summarised in Fig. 3. Additional file 5 contains the detailed risk of bias judgements per study. We were not able to access the full study report for two studies [46, 49] and assessed all domains as having an unclear risk of bias due to missing information. We judged two non-RCTs $[47,50]$ to have a high risk of selection bias. The remaining studies did not report adequately on sequence generation and allocation concealment and were judged to be of unclear risk of bias. All studies had a high risk of performance bias, as the nature of the interventions did not allow blinding of participants and personnel and most outcomes were measured subjectively. We judged the risk of attrition bias to be low for two studies $[47,50]$ and high for six studies $[40,41,52-56]$ due to high rates of loss-tofollow-up. The risk of attrition bias was unclear for the remaining studies.

\section{Effects of self-management interventions on outcomes Comparison 1: self-management interventions addressing one to two self-management domains vs control}

We included seven studies in this comparison [40, 42, 45, 46, 53-56]. One study, Peer-led Trauma Informed Cognitive Behavioral Therapy [45, 46], did not publish any outcome data in available articles and authors could not provide any data when contacted. Forest plots containing data for all outcomes are available in Additional file 6. The summary of findings and GRADE certainty of evidence ratings are presented in Table 5.

\section{Patient reported outcomes}

\section{Knowledge and understanding of illness}

Two studies found little to no difference between groups at three [42] and four [56] months follow-up.

\section{Confidence (self-efficacy for taking ART)}

One study, Cell Phone Support [40, 41], found a small increase in self-efficacy for health promotion and risk reduction (MD 0.35 95\% CI (0.01 to 0.69), $n=33$, very low

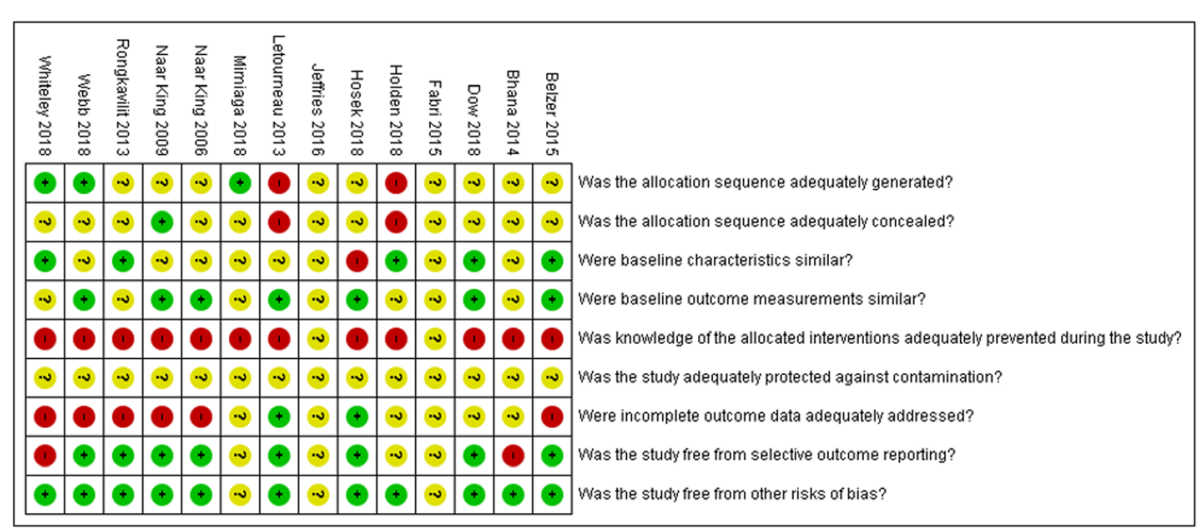

Fig. 3 Summary of risk of bias 
Table 5 Summary of Findings comparison 1

Summary of findings: Self-management interventions compared to control in adolescents living with HIV

Patient or population: Adolescents living with HIV; Setting: Low-, middle-, and high-income countries; Intervention: Self-management interventions with 1-2 components; Comparison: Usual care

\begin{tabular}{|c|c|c|c|c|c|}
\hline Outcome & $\begin{array}{l}\text { Follow- } \\
\text { up }\end{array}$ & $\begin{array}{l}\text { Pooled } \\
\text { effect } \\
(95 \% \mathrm{Cl})\end{array}$ & $\begin{array}{l}\text { No. of } \\
\text { participants } \\
\text { (studies) }\end{array}$ & $\begin{array}{l}\text { Certainty of } \\
\text { evidence } \\
\text { (GRADE) }\end{array}$ & Comments \\
\hline \multirow[t]{6}{*}{ Confidence } & $\begin{array}{l}3 \\
\text { months }\end{array}$ & $\begin{array}{l}\text { MD } 0.35 \\
(0.01 \text { to } 0.69)\end{array}$ & 33 (1 trial) & \multirow[t]{6}{*}{$\begin{array}{l}\text { ФOO० } \\
\text { VERY LOW a,b,c }\end{array}$} & \multirow{6}{*}{$\begin{array}{l}\text { HIV self-management interventions compared to usual care for ado- } \\
\text { lescents living with HIV may increase confidence at 3-month follow- } \\
\text { up and may make little or no difference to confidence at 4-, 6-, 9- } \\
\text { and 12-month follow-ups, but the evidence is very uncertain. }\end{array}$} \\
\hline & \multirow[t]{2}{*}{$\begin{array}{l}4 \\
\text { months }\end{array}$} & $\begin{array}{l}\text { MD } 0.00 \\
(-0.26 \text { to } \\
0.26)\end{array}$ & 96 (1 trial) & & \\
\hline & & $\begin{array}{l}\text { MD } 0.35 \\
(-2.12 \text { to } \\
2.82)\end{array}$ & 61 (1 trial) & & \\
\hline & $\begin{array}{l}6 \\
\text { months }\end{array}$ & $\begin{array}{l}\text { MD } 0.14 \\
(-0.32 \text { to } \\
0.60)\end{array}$ & 31 (1 trial) & & \\
\hline & $\begin{array}{l}9 \\
\text { months }\end{array}$ & $\begin{array}{l}\text { MD } 0.10 \\
(-0.17 \text { to } \\
0.37)\end{array}$ & 91 (1 trial) & & \\
\hline & $\begin{array}{l}12 \\
\text { months }\end{array}$ & $\begin{array}{l}\text { MD } 0.21 \\
(-0.22 \text { to } \\
0.64)\end{array}$ & 31 (1 trial) & & \\
\hline \multirow[t]{4}{*}{$\begin{array}{l}\text { Adherence (self- } \\
\text { reported) }\end{array}$} & $\begin{array}{l}3 \\
\text { months }\end{array}$ & $\begin{array}{l}\text { SMD } 0.19 \\
(-0.09 \text { to } \\
0.48)\end{array}$ & 198 (3 trials) & \multirow[t]{4}{*}{$\begin{array}{l}\text { ĐOOO } \\
\text { VERY LOW }{ }^{\mathrm{a}, \mathrm{b}, \mathrm{c}}\end{array}$} & \multirow{4}{*}{$\begin{array}{l}\text { HIV self-management interventions compared to usual care for ado- } \\
\text { lescents living with HIV may make little or no difference to self- } \\
\text { reported adherence at 3-, 6- and 9-month follow-ups, and may in- } \\
\text { crease adherence at 12-month follow-up, but the evidence is very } \\
\text { uncertain. }\end{array}$} \\
\hline & $\begin{array}{l}6 \\
\text { months }\end{array}$ & $\begin{array}{l}\text { SMD } 0.71 \\
(-0.02 \text { to } \\
1.44)\end{array}$ & 31 (1 trial) & & \\
\hline & $\begin{array}{l}9 \\
\text { months }\end{array}$ & $\begin{array}{l}\text { SMD } 0.11 \\
(-0.30 \text { to } \\
0.52)\end{array}$ & 91 (1 RCT) & & \\
\hline & $\begin{array}{l}12 \\
\text { months }\end{array}$ & $\begin{array}{l}\text { SMD } 1.16 \\
\text { (0.39 to } 1.93 \text { ) }\end{array}$ & 31 (1 trial) & & \\
\hline
\end{tabular}

\begin{tabular}{|c|c|c|c|c|c|}
\hline $\begin{array}{l}\text { Adherence } \\
\text { (Electronic pill } \\
\text { monitoring) }\end{array}$ & $\begin{array}{l}4 \\
\text { months }\end{array}$ & $\begin{array}{l}\text { SMD } 0.29(- \\
0.21 \text { to } 0.8)\end{array}$ & 61 (1 trial) & $\begin{array}{l}\text { } O O O \\
\text { VERY LOW } a, b, c\end{array}$ & $\begin{array}{l}\text { HIV self-management interventions compared to usual care for ado- } \\
\text { lescents living with HIV may make little or no difference to adherence } \\
\text { at 4-month follow-up, but the evidence is very uncertain. }\end{array}$ \\
\hline \multirow[t]{2}{*}{$\begin{array}{l}\text { Sexual risk } \\
\text { behaviour }\end{array}$} & $\begin{array}{l}4 \\
\text { months }\end{array}$ & $\begin{array}{l}\text { MD } 0.4 \\
(-0.76 \text { to } \\
1.56)\end{array}$ & 96 (1 trial) & $\begin{array}{l}\oplus O O O \\
\text { VERY LOW } a, b, c\end{array}$ & \multirow{2}{*}{$\begin{array}{l}\text { HIV self-management interventions compared to usual care for ado- } \\
\text { lescents living with HIV may make little or no difference to sexual risk } \\
\text { behaviour at 4- and 9-month follow-ups, but the evidence is very } \\
\text { uncertain. }\end{array}$} \\
\hline & $\begin{array}{l}9 \\
\text { months }\end{array}$ & $\begin{array}{l}M D-0.90 \\
(-2.39 \text { to } \\
0.59)\end{array}$ & 91 (1 trial) & & \\
\hline \multirow[t]{4}{*}{ Viral load (log 10) } & $\begin{array}{l}4 \\
\text { months }\end{array}$ & $\begin{array}{l}M D-0.12 \\
(-0.45 \text { to } \\
0.2)\end{array}$ & 157 (2 trials) & $\begin{array}{l}\oplus \oplus O O \\
L O W a, b\end{array}$ & \multirow{4}{*}{$\begin{array}{l}\text { HIV self-management interventions compared to usual care for ado- } \\
\text { lescents living with HIV may make little or no difference to viral load } \\
\text { at } 4-\text { and 9-month follow-ups. At } 6 \text { - and } 12 \text {-month follow-ups, HIV } \\
\text { self-management interventions compared to usual care may decrease } \\
\text { viral load, but the evidence is very uncertain. }\end{array}$} \\
\hline & $\begin{array}{l}6 \\
\text { months }\end{array}$ & $\begin{array}{l}\text { MD }-1.70 \\
(-2.65 \text { to }- \\
0.75)\end{array}$ & 30 (1 trial) & $\begin{array}{l}\text { 円OOO } \\
\text { VERY LOW a,b,c }\end{array}$ & \\
\hline & $\begin{array}{l}9 \\
\text { months }\end{array}$ & $\begin{array}{l}\mathrm{MD}-0.02 \\
(-0.30 \text { to } \\
0.26)\end{array}$ & 237 (2 trials) & $\begin{array}{l}\oplus \oplus O O \\
L O W a, b\end{array}$ & \\
\hline & $\begin{array}{l}12 \\
\text { months }\end{array}$ & $\begin{array}{l}\mathrm{MD}-1.00 \\
(-1.89 \text { to } \\
-0.11)\end{array}$ & 31 (1 trial) & $\begin{array}{l}\text { ФOOO } \\
\text { VERY LOW } \mathrm{a}, \mathrm{b}, \mathrm{c}\end{array}$ & \\
\hline Depression & $\begin{array}{l}3 \\
\text { months }\end{array}$ & $\begin{array}{l}\text { SMD }-0.27 \\
(-0.56 \text { to } \\
0.01)\end{array}$ & 194 (3 trials) & $\begin{array}{l}\oplus O O O \\
\text { VERY LOW } \\
\text { a,b,c }\end{array}$ & $\begin{array}{l}\text { HIV self-management interventions compared to usual care for ado- } \\
\text { lescents living with HIV may make little or no difference to depression } \\
\text { at 3-, 6-, 9- and 12-month follow-ups, but the evidence is very } \\
\text { uncertain. }\end{array}$ \\
\hline
\end{tabular}


Table 5 Summary of Findings comparison 1 (Continued)

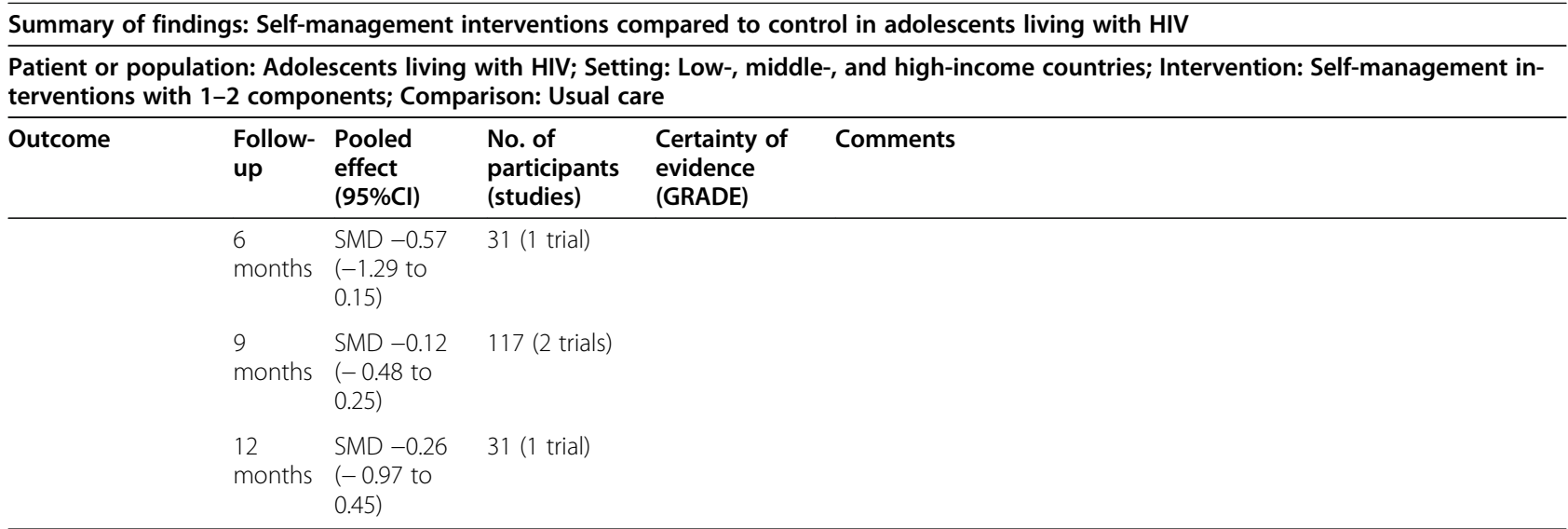

Cl Confidence interval, MD Mean difference, SMD Standardised mean difference GRADE Working Group: Grades of evidence

High certainty: We are very confident that the true effect lies close to that of the estimate of the effect

Moderate certainty: We are moderately confident in the effect estimate: The true effect is likely to be close to the estimate of the effect, but there is a possibility that it is substantially different

Low certainty: Our confidence in the effect estimate is limited: The true effect may be substantially different from the estimate of the effect

Very low certainty: We have very little confidence in the effect estimate: The true effect is likely to be substantially different from the estimate of effect

Footnotes: Explanation of GRADE certainty of evidence

${ }^{a}$ Downgraded by 1 for serious concerns about risk of bias in at least one domain

b Downgraded by 1 for indirectness, as studies did not only include adolescents (age 10 to 19)

c Downgraded by 1 for serious concerns about imprecision with wide $95 \% \mathrm{Cl}$ intervals and small sample sizes

certainty evidence) in the group receiving the selfmanagement intervention compared to the control group at the three-month follow-up. At the four-month follow-up, two studies $[54,56]$ found little to no difference between groups (very low certainty evidence). At the six [40, 41], nine [54] and 12-month [40, 41] followups, studies found little to no difference between groups (very low certainty evidence). One study [42] did not report data for this outcome.

\section{Motivation for taking ART}

Studies found little to no difference between groups at three [40,41], four [54], six [40, 41], nine [40, 41, 54], and 12-month [40, 41] follow-ups.

\section{Mindfulness}

One study, Mindfulness-Based Stress Reduction [55], found a slight increase in mindfulness scores in the group receiving the self-management intervention compared to the control group (MD 0.65, 95\%CI 0.06 to $1.24, n=71)$ at the three-month follow-up.

\section{Social support}

One study, the Vuka Family Programme [42], found a slight increase in youth and caregiver communication and comfort scores (MD 0.8, 95\%CI 0.31 to $1.28, n=65$ ) among participants receiving the self-management intervention compared to the control group at the threemonth follow-up. At the four-month follow-up, one study [56] found little to no difference between groups offering social support for adherence.

None of the included studies reported on participation in care, interpersonal skills or networks and communication.

\section{Patient behaviours \\ Adherence to ART}

The pooled effect of three studies included in the metaanalysis $[42,55,56]$ showed little to no difference in self-reported adherence between groups (SMD 0.19, $95 \%$ CI -0.09 to $0.48 ; n=198,3$ studies, very low certainty evidence) at the three to four-month follow-up. One study [56] also used electronic pill monitoring to measure adherence at the three-month follow-up and found little to no difference between groups (SMD 0.29, $95 \%$ CI -0.231 to $0.80, n=61$, very low certainty evidence). Two studies found little to no difference between groups at six [40, 41] and nine-month [54] follow-ups (very low certainty evidence). One study, Cell Phone Support [40, 41], found a large increase in adherence scores in the group receiving the self-management intervention at the 12-month follow-up (SMD 1.16, 95\%CI 0.39 to $1.93, n=33$, very low certainty evidence).

\section{Sexual risk behaviour}

One study [54] found little to no difference between groups at the four and nine-month follow-up (very low certainty evidence). 


\section{Self-care abilities (substance use)}

Studies found little to no difference between groups at the three [40, 41], four [54], six [40, 41] and nine-month [40, 41, 54] follow-ups. One study, Cell Phone Support $[40,41]$, found a decrease in substance use among participants receiving the self-management intervention at the 12-month follow-up (MD -5.38, 95\%CI - 10.16 to $0.60, n=32$ ) compared to the control group.

\section{Healthcare utilisation}

One study $[40,41]$ found little to no difference between groups that made healthcare visits over 12 weeks prior to assessments done at three, six, nine and 12 months.

None of the included studies reported on symptom management or retention in care.

\section{Health status}

\section{Viral suppression}

One study [55] reported on the number of participants with a viral $\operatorname{load}(\log 10)$ of less than 2 at the threemonth follow-up and found little to no difference between groups (very low certainty evidence). The pooled effect of two studies $[54,56]$ showed little to no difference in viral load $(\log 10)$ between groups (MD -0.12, $95 \% \mathrm{CI}-0.42$ to $0.20, n=157$, low certainty evidence) at the four-month follow-up. One study, Cell Phone Support $[40,41]$, found a decrease in the viral load $(\log 10)$ among participants receiving the self-management intervention, compared to the control group, at the sixmonth follow-up (MD -1.70, 95\%CI -2.65 to -0.75 , $n=30$, very low certainty evidence). The pooled effect of two studies $[53,54]$ found little to no difference in viral load $(\log 10)$ between groups at the nine-month followup (MD - $0.02,95 \% \mathrm{CI}-0.30$ to $0.26, n=237$, low certainty evidence). One study, Cell Phone Support [40, 41], found a decrease in viral $\operatorname{load}(\log 10)$ among participants receiving the self-management intervention compared to the control group at the 12-month follow-up (MD -1.00, $95 \% \mathrm{CI}-1.89$ to $-0.11, n=31$, very low certainty evidence).

\section{CD4 count}

One study $[40,41]$ found little to no difference between groups at the three-month follow-up.

\section{Quality of life}

One study, Mindfulness-Based Stress Reduction [55], found a slight increase in life satisfaction scores among participants receiving the self-management intervention compared to the control group (MD 0.57, 95\%CI 0.01 to $1.13, n=72)$ at the three-month follow-up, but found little to no difference for illness burden and illness anxiety.

\section{Emotional health}

The pooled effect for two studies [37, 48, 53] showed little to no difference between groups for perceived stress at the three-month follow-up (MD -0.27, 95\%CI - 0.66 to $0.11, n=105)$. One study, Cell Phone Support [40, 41], found little to no difference between groups at six and nine months, and found a slight decrease in perceived stress among participants who received the selfmanagement intervention compared to the control group at the 12-month follow-up (MD -1.90, 95\%CI 3.53 to $-0.27, n=31$ ). One study [54] reported on anxiety and found little to no difference between groups at the four and nine-month follow-ups.

\section{Mental health}

The pooled effect of three studies [40-42, 54] showed little to no difference in depression scores between groups (SMD $-0.27,95 \% \mathrm{CI}-0.56$ to $0.01, n=194$, very low certainty evidence) at the three-month follow-up. There was little to no difference between groups' depression scores at the six $[40,41]$, nine $[40,41,54]$ and 12 month $[40,41]$ follow-up (very low certainty evidence).

\section{Psychological health}

The pooled effect of two studies [40, 41, 55] showed litthe to no difference between groups for problem-solving (SMD 0.33, 95\%CI -0.05 to $0.72, n=105$ ) at the threemonth follow-up. One study $[40,41]$ found little to no difference between groups for problem-solving at the six, nine and 12-month follow-up. The pooled effect of two studies $[40,41,55]$ showed little to no difference between groups for distraction at the three-month followup (SMD 0.17, 95\%CI -0.22 to $0.55, n=105$ ). One study $[40,41]$ found little to no difference between groups for distraction at the six, nine and 12-month follow-ups.

None of the included studies reported on physical health.

\section{Impact}

None of the included studies reported on hospitalisation, co-morbidities, all-cause mortality, HIV transmission or employment.

\section{Comparison 2: self-management interventions addressing all three components vs control groups}

We included five studies in this comparison [43, 44, 47, $49,51,52]$. Forest plots containing data for all outcomes are available in Additional file 6. The summary of findings and GRADE certainty of evidence ratings are presented in Table 6 . 


\section{Patient reported outcomes Confidence}

One study, Sauti ya Vijana [43, 44], reported on the internal stigma score (negative self-image) and found little to no difference in scores at the six-month follow-up (very low certainty evidence). One study [51] did not report data for this outcome.

One study, Positive STEPS [51], measured social support and interpersonal skills but did not report any data for these outcomes. None of the included studies reported on knowledge and understanding of illness, motivation for taking ART, mindfulness, participation in care or networks and communication.

\section{Patient behaviours}

\section{Adherence to ART}

Two studies, Sauti ya Vijana and Positive STEPS [43, 44, 51], were included in the meta-analysis and showed an increase in adherence among participants receiving the self-management intervention compared to the control group that formed the baseline at the four or six-month follow-up (SMD 0.67, 95\%CI 0.27 to $1.07, n=107$, very low certainty evidence). One study $[43,44]$ also reported ART hair concentration as a measure of adherence and found little to no difference between groups and there was no change from the baseline to the six-month follow-up (very low certainty evidence). One study, Stepping Stones [47], reported on the number of participants that had achieved over 95\% adherence based on pill counting and self-reporting at the nine-month followup. They found that participants receiving the selfmanagement intervention were $41 \%$ more likely to have achieved over $95 \%$ adherence compared to the control group (risk ratio (RR) $1.41,95 \%$ CI 1.20 to $1.65, n=177$, very low certainty evidence). One study measured adherence but did not report data [49].

\section{Sexual risk behaviour}

One study [52] found little to no difference between groups at three months follow-up.

\section{Self-care abilities (substance use)}

Naar-King et al. (2006) [52] found little to no difference between groups for alcohol use, as well as for marijuana use. One study, UCare4Life [49], did not report any data for this outcome.

None of the included studies reported on symptom management, retention in care or healthcare utilisation.

\section{Health status}

\section{Viral suppression}

One study, Healthy Choices [52], found a decrease in viral load $(\log 10)$ among participants receiving the selfmanagement intervention compared to the control group at the three-month follow-up (MD -0.66, 95\%CI -1.21 to -0.11 , very low certainty evidence). Dow $(2018,2020)[43,44]$ found little to no difference in viral load $(\log 10)$ between groups at the six-month follow-up (very low certainty evidence). One study [49] did not report any data for this outcome.

\section{CD4 count}

One study, Stepping Stones [47], found an increase in CD4 count among participants receiving the selfmanagement intervention compared to the control group at the nine-month follow-up (MD 156.82, 95\%CI 43.48 to $270.16, n=177$ ).

\section{Psychological/mental health}

One study, Sauti ya Vijana [43, 44], found little to no difference between groups for depression and other mental health measures.

None of the included studies reported on quality of life, emotional health or physical health.

\section{Impact}

None of the included studies reported on hospitalisation, co-morbidities, all-cause mortality, HIV transmission or employment.

\section{Comparison 3: self-management interventions vs other interventions with self-management components}

We included two studies in this comparison $[48,50]$. Hosek et al. (2018) (Project ACCEPT for Newly HIV Diagnosed Youth) analysed longitudinal data collected at three, six and 12 months post-intervention, and reported longitudinal outcomes associated with the intervention group over time [48]. Letourneau et al. (2013) (Multisystemic Therapy for Poorly Adherent Youth) collected data at three, six and 12 months post-intervention and reported the change in outcome slopes between groups over time [50]. Neither of the studies reported means and standard deviations at particular follow-up periods. Both studies had controls that included selfmanagement components. For example, the control for Project ACCEPT was health education that included all three self-management components and for Multisystemic Therapy, the control (usual care with motivational interviewing) included one self-management component.

\section{Patient reported outcomes Confidence}

Project ACCEPT [48] found little to no difference in perceived HIV stigma scores between groups over time.

\section{Social support}

One study, Project ACCEPT [48], found little to no difference between groups over time. 


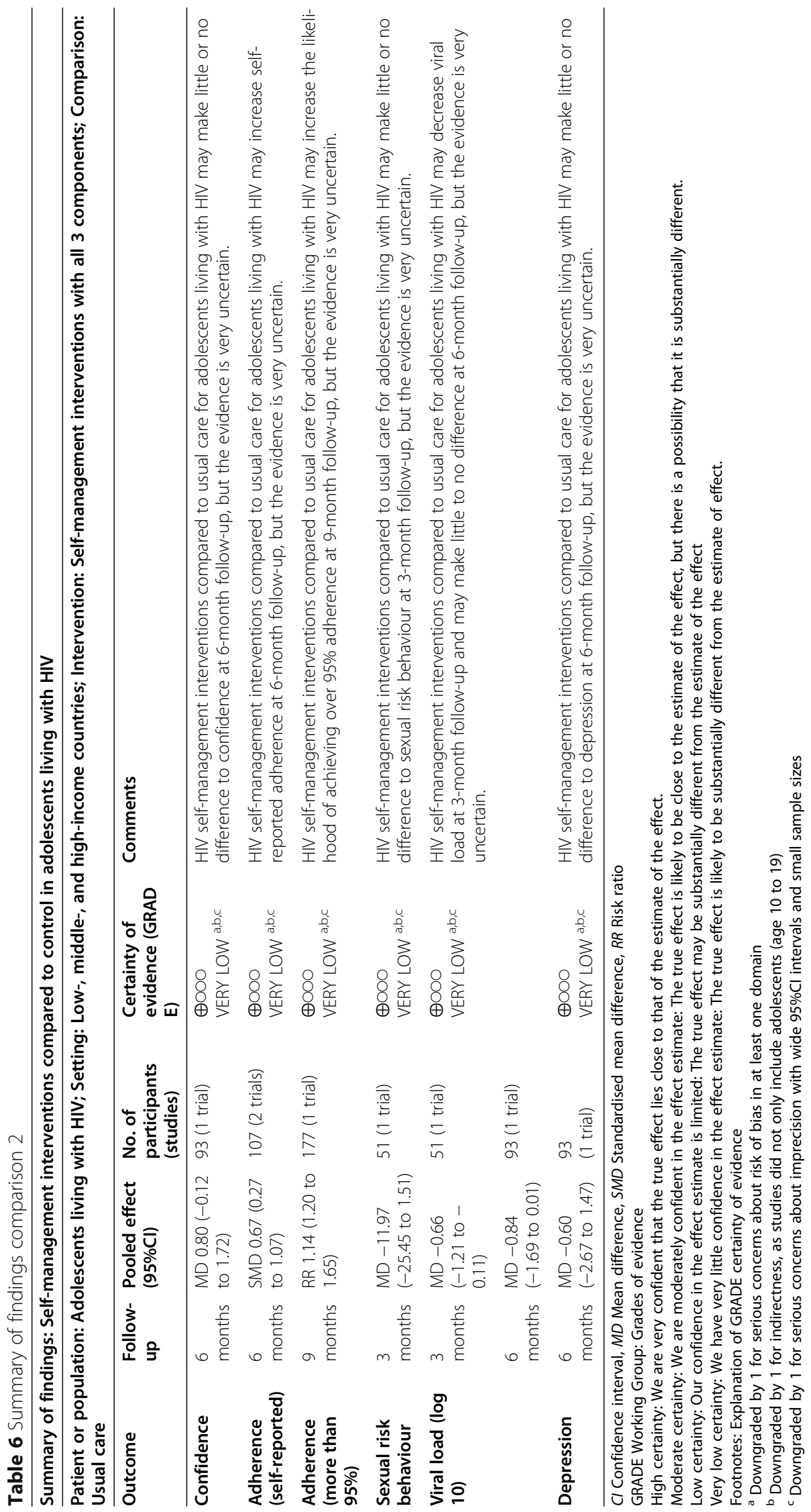




\section{Networks and communication}

One study, Project ACCEPT [48], found little to no difference in engagement with healthcare providers between groups over time.

None of the included studies reported on knowledge and understanding of illness, motivation for taking ART, mindfulness, participation in care or interpersonal skills.

\section{Patient behaviours}

\section{Adherence to ART}

Project ACCEPT [48] found a greater likelihood of using HIV medications over time in the intervention group compared to the control group (OR 2.33, 95\%CI 1.29 to 4.21). However, they found little to no difference between groups over time in terms of the self-reported adherence questionnaire. Multisystemic Therapy [50] found little to no difference in the rate of change in ART adherence between groups.

\section{Healthcare utilisation}

Project ACCEPT [48] found little to no difference between groups over time in terms of appointment adherence and number of medical visits.

None of the included studies reported on sexual risk behaviour, self-care abilities (substance use), symptom management or retention in care.

\section{Health status}

\section{Viral suppression}

Project ACCEPT and Multisystemic Therapy [48, 50] found a decrease in viral load over time in the intervention group compared to the control group.

\section{CD4 count}

Both studies $[48,50]$ found little to no difference in CD4 count over time between groups.

\section{Quality of life}

Project ACCEPT [48] found little to no difference between groups over time.

Mental/psychological health: One study, Project ACCE $P T$ [48], found little to no difference in psychological distress between groups over time.

None of the included studies reported on emotional or physical health.

\section{Impact}

None of the included studies reported on hospitalisation, co-morbidities, all-cause mortality, HIV transmission or employment.

\section{Discussion}

This systematic review evaluated the effectiveness of self-management interventions for improving health- related outcomes of ALHIV and aimed to identify intervention components that are effective, particularly in low-resource settings with a high HIV burden.

We included 14 studies in this review. Although we planned to include adolescents aged 10-19, most studies included young people up to 24 years and only one study reported stratified data. Interventions were heterogeneous, although the self-management components as depicted in the logic model (Fig. 1) could be identified. Most of the interventions addressed at least two selfmanagement domains, with self-regulation the most often targeted. Interventions were primarily delivered by trained counsellors via face-to-face individual education/ counselling sessions in healthcare settings. Intervention duration was between two and 8 months and the longest follow-up was 12 months. Few studies $(n=4)$ were conducted in low-resource settings, although we identified three ongoing studies that are being conducted in Africa. Interventions in a low-resource setting such as Africa (Vuka Family Programme; Sauti Ya Vijana, Peer-led Trauma Informed CBT, and Stepping Stones) predominantly used peers or lay healthcare workers as delivery agents and used group education/counselling, which may be more relevant in low-resource high HIV burden settings.

We generally found little to no difference in patient reported, behavioural and health outcomes across time, irrespective of the number of components addressed or the comparison. However, positive trends in the expected direction were observed. Variations in the definitions and imprecise measurement of patient-reported outcomes may have contributed to studies not showing an effect between groups. Furthermore, outcomes such as self-efficacy require continuous counselling [23] and follow-up periods might have been inadequate. We found small effects for adherence and viral suppression at the six, nine and 12-month follow-ups.

Although we observed clinical heterogeneity - linked to interventions, participants and outcome measurement - findings were strikingly consistent across studies. We downgraded the evidence to very low certainty for most of the key outcomes due to imprecision (wide confidence intervals and small sample sizes); indirectness as most studies did not specifically include adolescents aged 10-19; and study limitations due to concerns about risk of bias across studies.

We also did not find any specific trends with regards to the number of self-management components (domains) addressed, types of interventions (e.g. individual vs group), the delivery method (e.g. face-to-face vs ICT) or the delivery agent (healthcare worker, peer or trained counsellor) that appeared to be more effective for certain outcomes. For example, Cell Phone Support increased adherence and viral suppression and reduced substance 
use and perceived stress. The peer-delivered mental health intervention, Sauti ya Vijana [43, 44]; Positive Steps, an individual technology-based intervention [51]; and Stepping Stones, a group-based intervention [47], all reported increased adherence in the intervention groups compared to the control groups. The Healthy Choices intervention [52] found a decrease in viral load and Sauti ya Vijana [43, 44] reported an increase in CD4. Our findings suggest that the Vuka Family Programme [42] was more effective than the iPhone Game [56] for increasing social support. However, the perception of support may differ as the Vuka Family Programme focused on pre-adolescents whereas the iPhone Game targeted older adolescents. Studies that specifically focused on addressing psychological and patient-reported outcomes, for example Mindfulness-Based Stress Reduction [55], may be more appropriate to improve outcomes such as mindfulness and quality of life. Another explanation for not identifying specific effective components across studies may be that many interventions used combinations of delivery methods and adjusted the intervention to the context. It, therefore, appears that interventions for ALHIV should be tailored to the individual (specifically at the developmental stage), social and health system contexts, and the specific selfmanagement abilities and outcomes targeted.

To our knowledge, this is the first systematic review on the effectiveness of self-management interventions for ALHIV. Existing systematic reviews evaluating a variety of self-management interventions focussing on adults living with HIV reported improvements in most self-management outcomes including physical, psychosocial, health knowledge and behavioural outcomes [26, 27]. Abera et al. (2020) found that a combination of selfmanagement interventions including skills training, phone counselling using manuals and technologyassisted interventions (phone and web-based) generally improved outcomes, especially adherence, quality of life and symptom management. Peer-based skills interventions were found to likely improve psychological outcomes and quality of life, but less so for behaviour and physical outcomes [23].

Other reviews specifically focused on the effectiveness of self-management interventions using $m$-health or ICT. Cooper et al. (2017) found that m-health interventions for self-management were predominantly delivered through SMS and that it affected adherence, viral load, mental health and social support [68], whereas Tufts et al. (2015) reported that $\mathrm{m}$-health interventions for African-American women were mostly still exploratory and focused on adherence only [28]. In their review on communication technologies in self-management, Zhang and $\mathrm{Li}$ (2017) recommended that more research is needed to explore ICT interventions amongst people from low socio-economic backgrounds and low-resource settings [29]. Similarly, our findings indicate that Cell Phone Support [40, 41], SMS reminders from UCare4Life [49] and Positive Steps (that used SMS as the first step) [51] were $\mathrm{m}$-health/ICT interventions used most often. All these studies were conducted in the USA. Only one study used a gaming platform [56]. Although our review suggests that these interventions may improve some outcomes, there is no evidence of their effectiveness in lowresource settings and the existing evidence is very uncertain. Self-management interventions have also been used and studied in other chronic conditions. One review [25] found that self-management interventions for young people with chronic conditions were effective for medical management (disease knowledge and adherence) if they were provided individually in a clinic or home setting by a mono-disciplinary team. They found conflicting evidence regarding the effect on psychological outcomes and quality of life. Interventions focused on dealing with or coping with a chronic condition (role/emotionalmanagement) and may be effective if provided individually through telemedicine that facilitates peer support [25]. A review by Sattoe et al. (2015) found that selfmanagement support interventions neglected psychosocial challenges experienced by chronically ill young people [9]. Although many of the interventions in our review targeted adherence or viral suppression, they addressed multiple self-management domains. Selfregulation was addressed most frequently, while social facilitation was addressed least frequently. Selfregulation, especially coping with a stigmatised condition such as HIV, is an important component of HIV selfmanagement for adolescents. Social facilitation and active participation in care was shown to correlate with improved health-related quality of life and adherence amongst ALHIV in South Africa [21].

We followed rigorous methods to conduct our systematic review. We used a logic model to identify and unpack various aspects of the interventions and outcomes as well as used this to pre-specify the eligibility criteria for our review. Although we included different types of self-management interventions, we classified the interventions according to the domains of the IFSMT, which may limit the application to other frameworks. Various strategies and behaviour change interventions can be used to enhance self-management abilities. For example, the Behaviour Change Taxonomy (BCT) uses 16 clusters to characterise interventions based on their content [69]. The IFSMT domain of knowledge and beliefs can be addressed by using the techniques of shaping knowledge, natural consequences and self-belief. Self-regulation can be enhanced by several BCT taxonomy components: goals and planning, feedback and monitoring, comparison of outcomes, regulation, and identity. Social 
facilitation can be improved by social support, comparison of behaviour, and antecedents.

Our search of the literature was comprehensive and included multiple electronic databases, trial registries and grey literature. We did not have any language restrictions, although we only found studies published in English. We assessed certainty of evidence using the GRADE approach; few of the previous systematic reviews provided a grading of the evidence. Studies included in our review were heterogenous in terms of participants, interventions, and outcomes. We were, therefore, not able to explore the impact of the intervention delivery method, agent and participant characteristics. Furthermore, most studies included participants beyond 19 years of age (young people) and did not stratify data according to age groups. This precluded subgroup analysis. We noted that some studies selected participants based on high-risk behaviour or nonadherence. It may be that self-management interventions have a greater effect if implemented amongst high-risk groups or those newly diagnosed with HIV [26].

Our review findings may be particularly important for researchers who are in the process of designing selfmanagement interventions. Currently the evidence is too uncertain to make any recommendations for programme components that may be effective. Our review focused on assessing the effectiveness of self-management interventions and did not address questions linked to ALHI V's perceptions and experiences of these interventions, costs, and implementation issues.

None of the included studies reported on costeffectiveness or impact outcomes that may be used to influence policy on a larger scale. Aantjes et al. (2014) previously found that self-management intervention models have low applicability in sub-Saharan Africa as most interventions are led by health-professionals whereas peerled models may be more sustainable in low-resource settings [70].

\section{Conclusion}

Existing evidence on the effectiveness of self-management interventions compared to control groups for improving health-related outcomes of ALHIV is very uncertain. We, therefore, do not know whether self-management interventions for ALHIV lead to better or worse behaviour and health outcomes or whether they make no difference at all. Despite this, there is a need to support ALHIV to cope with and manage a life-long condition. Implementation of self-management interventions should take into consideration the individual, social and healthcare contexts. Interventions delivered by peers or lay healthcare workers may be more feasible and sustainable in low-resource settings with a high HIV burden.
Further rigorous studies are needed to evaluate the effectiveness of self-management interventions among ALHIV living in Africa, which has the greatest burden of HIV/AIDS. This includes research on the use of cellphone and ICT-based interventions. Furthermore, the science of self-management would benefit if studies used a taxonomy or logic models to match intervention outcomes with intervention components, including impact outcomes such as hospitalisations, mortality, and employment, so that comparable results can be provided. Randomised controlled trials with larger sample sizes that follow participants over longer periods may improve the certainty of the evidence. A qualitative synthesis of ALHIV's experiences of various self-management interventions will be useful to evaluate reasons for lack of effectiveness of these on patient-reported and psychological outcomes. This can help to inform the development of future interventions.

\section{Abbreviations}

ALHIV: Adolescents living with HIV; ART: Antiretroviral treatment; CBAs: Controlled before-after studies; CD4: Cluster of differentiation 4; EPOC: Cochrane Effective Practice and Organisation of Care; GRADE: Grades of Recommendation, Assessment, Development and Evaluation; HIV: Human Immunodeficiency Virus; ICT: Information and Communication Technologies; NRCTs: Non-randomised controlled trials; PHIV: People living with HIV; PROSPERO: International Prospective Register of Systematic Reviews; RCTs: Randomised controlled trials; TIDier: Template for Intervention Description and Replication; WHO: World Health Organisation

\section{Supplementary Information}

The online version contains supplementary material available at https://doi. org/10.1186/s12879-021-06072-0.

Additional file 1. Prisma checklist and appendix.

Additional file 2. Search histories.

Additional file 3. Summary of ongoing studies.

Additional file 4. Excluded studies with reasons.

Additional file $\mathbf{5}$. Risk of bias tables.

Additional file 6 . Forest plots.

\section{Acknowledgements}

We would like to thank Ms. Anel Schoonees for conducting the search and Dr. Alfred Musekiwa for advice on some statistical issues.

\section{Authors' contributions}

Both authors contributed to the writing of the protocol, conducted the review and wrote the manuscript. The authors read and approved the final manuscript.

\section{Authors' information}

Talitha Crowley (PhD) is a senior lecturer at the Department of Nursing and Midwifery at the Faculty of Medicine and Health Sciences, Stellenbosch University, Cape Town, South Africa.

Anke Rohwer (PhD) is a senior researcher at the Centre for Evidence-based Health Care, Division of Epidemiology and Biostatistics, Department of Global Health, Faculty of Medicine and Health Sciences, Stellenbosch University, Cape Town, South Africa. 


\section{Funding}

We would like to acknowledge funding from Stellenbosch University Early Career Research Funding and the National Research Foundation (NRF) (Ref TTK180420323095).

\section{Availability of data and materials}

This systematic review is based on existing published and unpublished study reports. All data analysed during this study are included in this published article and its supplementary information files.

\section{Declarations}

\section{Ethics approval and consent to participate}

The systematic review is part of a larger study that obtained approval from the Health Research Ethics Committee of Stellenbosch University (\#:N18/06/ 064) on 09/10/2018.

\section{Consent for publication}

Not applicable.

\section{Competing interests}

The authors have no competing interests to declare.

\section{Author details}

${ }^{1}$ Department of Nursing and Midwifery, Faculty of Medicine and Health Sciences, Stellenbosch University, Cape Town, South Africa. ${ }^{2}$ Centre for Evidence-based Health Care, Division of Epidemiology and Biostatistics, Department of Global Health, Faculty of Medicine and Health Sciences, Stellenbosch University, Cape Town, South Africa.

Received: 13 January 2021 Accepted: 9 April 2021

Published online: 07 May 2021

\section{References}

1. UNICEF. HIV and AIDS in adolescents [Internet]. 2020. Available from: https:// data.unicef.org/topic/adolescents/hiv-aids/

2. World Health Organization. IMAI one day orientation on adolescents living with HIV. 2010. Available from https://www.who.int/maternal_child_a dolescent/documents/fch_cah_9789241598972/en/

3. Van Staa A. On your own feet: adolescents with chronic conditions and their preferences and competencies for care. the Netherlands: Erasmus University Rotterdam; 2012. Available from https://www.researchgate.net/ publication/254821532_On_Your_Own_Feet_Preferences_and_ Competencies_for_Care_of_Adolescents_with_Chronic_Conditions

4. Sohn AH, Hazra R. The changing epidemiology of the global paediatric HIV epidemic: keeping track of perinatally HIV-infected adolescents. J Int AIDS Soc. 2013;16(1):1-8. https://doi.org/10.7448/IAS.16.1.18555.

5. Webb D, Cluver L, Luo C. Evolution or extinction? Paediatric and adolescent HIV responses in the agenda 2030 era. J Int AIDS Soc. 2018;21(S1):8-10. https://doi.org/10.1002/jia2.25071.

6. Mofenson LM, Cotton MF. The challenges of success: adolescents with perinatal HIV infection. J Int AIDS Soc. 2013;16(18650):15-7.

7. Grimsrud A, Bygrave H, Wilkinson L. The case for family-centered differentiated service delivery for HIV. J Int AIDS Soc. 2018;78(2):2016-9. https://doi.org/10.1097/QAl.0000000000001733.

8. Grady PA, Gough LL. Self-management: a comprehensive approach to management of chronic conditions. Am J Public Health. 2014;104(8):25-31. https://doi.org/10.2105/AJPH.2014.302041.

9. Sattoe JNT, Bal MI, Roelofs PDDM, Bal R, Miedema HS, Van Staa A. Patient education and counseling self-management interventions for young people with chronic conditions: a systematic overview. Patient Educ Couns. 2015; 98(6):704-15. https://doi.org/10.1016/j.pec.2015.03.004.

10. Modi AC, Hommel K, Hood K, Cortina S. Pediatric self-management: a framework for research, practice, and policy. Pediatrics. 2012;129(June 2014): e473-86. https://doi.org/10.1542/peds.2011-1635.

11. Sawin KJ. Definitions, frameworks, and theoretical issues in selfmanagement. J Pediatr Rehabil Med An Interdiscip Approach. 2017;10(3-4): 169-76. https://doi.org/10.3233/PRM-170461.

12. Bodenheimer T. Interventions to improve chronic illness care: evaluating their effectiveness. Dis Manag. 2003;6(2):63-71. https://doi.org/10.1089/1093 50703321908441.
13. Cuthbert CA, Samawi HH, Hemmelgarn BR, Cheung WYCC. Effectiveness and components of self-management interventions in adult cancer survivors: a protocol for a systematic review. Syst Rev. 2018;7(238). https:// doi.org/10.1186/s13643-018-0902-7.

14. Corbin J, Strauss A. Unending work and care: managing chronic illness at home. San Francisco: Jossey-Bass; 1988.

15. Holman H, Lorig K. Patient self-management: a key to effectiveness and efficiency in care of chronic disease. Public Health Rep. 2004;119(June):23943. https://doi.org/10.1016/j.phr.2004.04.002.

16. Ryan P, Sawin KJ. The individual and family self-management theory: background and perspectives on context, process, and outcomes. Nurs Outlook. 2010;57(4):217-25. https://doi.org/10.1016/j.outlook.2008.10.004.

17. Schilling LS, Dixon JK, Knafl KA, Lynn MR, Murphy K, Dumser S, et al. A new self-report measure of self-management of type 1 diabetes for adolescents. Nurs Res. 2009:58(4):228-36. https://doi.org/10.1097/NNR.0b013e3181ac142a.

18. Bernardin KN, Toews DN, Restall GJ, Vuongphan L. Self-management interventions for people living with human immunodeficiency virus: a scoping review. Can J Occup Ther. 2013;80(5):314-27. https://doi.org/10.11 77/0008417413512792.

19. Grey M, Schulman-Green D, Knafl K, Reynolds NR. A revised self- and family management framework. Nurs Outlook. 2015;63(2):162-70. https://doi.org/1 0.1016/j.outlook.2014.10.003.

20. Mehraeen E, Safdari R, Seyedalinaghi S, Mohammadzadeh N, Arji G. Identifying and validating requirements of a mobile-based selfmanagement system for people living with HIV. Stud Health Technol Inform. 2018;248:140-7. 29726430.

21. Crowley T, Van der Merwe A, Kidd M, Skinner D. Adolescent human immunodeficiency virus self-management: associations with treatment adherence, viral suppression, sexual risk behaviours and health-related quality of life. South Afr J HIV Med. 2020;21(1):1-11. https://doi.org/10.4102/ SAJHIVMED.V2111.1054

22. Bodenheimer T, Lorig K. Patient self-management of chronic disease in primary care. Am Med Assoc. 2002;288(19):2469-75. https://doi.org/10.1001/ jama.288.19.2469.

23. Abera H, Id A, Marshall A, Harvey G. Interventions to improve self-management of adults living with HIV on antiretroviral therapy: a systematic review. PLoS One. 2020;15(5):1-22. https://doi.org/10.1371/journal.pone.0232709.

24. Rohwer A, Pfadenhauer L, Burns J, Brereton L, Gerhardus A. Series: clinical epidemiology in South Africa. Paper 3: logic models help make sense of complexity in systematic reviews and health technology assessments. J Clin Epidemiol. 2017;83:37-47. https://doi.org/10.1016/j.jclinepi.2016.06.012.

25. Bal MI, Sattoe JNT, Roelofs PDDM, Bal R, Van Staa A, Miedema HS. Patient education and counseling exploring effectiveness and effective components of self-management interventions for young people with chronic physical conditions: a systematic review. Patient Educ Couns. 2016; 99(8):1293-309. https://doi.org/10.1016/j.pec.2016.02.012.

26. Millard T, Hons OT, Elliott J, Girdler S. Self-management education programs for people living with HIV/AIDS. AIDS Patient Care STDs. 2013;27(2):103-13. https://doi.org/10.1089/apc.2012.0294.

27. Nkhoma K, Norton C, Sabin C, Winston A, Merlin J, Harding R. Selfmanagement interventions for pain and physical symptoms among people living with HIV: a systematic review of the evidence. J Acquir Immune Defic Syndr. 2018;79(2):206-25. https://doi.org/10.1097/QAI.0000000000001785.

28. Tufts KA, Johnson KF, Shepherd JG, Lee J, Mahan LB, Kim MT. Novel interventions for HIV self-management in African American women: a systematic review of mHealth interventions. J Assoc Nurses AIDS Care. 2015; 26(2):139-50. https://doi.org/10.1016/j.jana.2014.08.002.

29. Zhang Y, Li X. International Journal of Information Management Uses of information and communication technologies in HIV self-management: A systematic review of global literature. Int J Inf Manag. 2017;37(2):75-83. https://doi.org/10.1016/j.jijinfomgt.2016.11.003

30. Wright C. Self-management of HIV and diabetes in African American women. Diabetes Educ. 2018;44(5):419-34. https://doi.org/10.1177/0145721 718794879

31. Petticrew M, Shekelle P, Stewart LA, Group P. Preferred reporting items for systematic review and meta-analysis protocols (PRISMA-P) 2015: elaboration and explanation. BMJ. 2015;7647(January):1-25. https://doi.org/10.1136/bmj. g7647.

32. Cochrane Effective Practice and Organisation of Care (EPOC). Suggested risk of bias criteria for EPOC reviews. EPOC Resources for review authors, 2017. [Internet] Available from: https://epoc.cochrane.org/sites/epoc.cochrane.org/ 
files/public/uploads/Resources-for-authors2017/suggested_risk_of_bias_ criteria_for_epoc_reviews.pdf.

33. United Nations Department of Economic and Social Affairs (UNDESA). Definition of youth; 2008. p. 1-3. [Internet] Available from: https://www.un org/esa/socdev/documents/youth/fact-sheets/youth-definition.pdf

34. Hoffmann TC, Glasziou PP, Barbour V, Macdonald H. Better reporting of interventions: template for intervention description and replication (TIDieR) checklist and guide. BMJ. 2014;1687(March):1-12. https://doi.org/10.1136/ bmj.g1687.

35. Higgins J, Thomas J. Cochrane handbook for systematic reviews of interventions. Version 6.1. [Internet]. 2020. Available from: https://training. cochrane.org/handbook/current.

36. Oxman AD. GRADE Working Group: grading quality of evidence and strength of recommendations. BMJ. 2004;328(June). https://doi.org/10.1136/ bmi.328.7454.1490

37. Guyatt G, Oxman AD, Akl EA, Kunz R, Vist G, Brozek J, et al. GRADE guidelines: 1. Introduction-GRADE evidence profiles and summary of findings tables. J Clin Epidemiol. 2011;64(4):383-94 [cited 2019 Sep 11]. Available from: https://www.sciencedirect.com/science/article/abs/pii/ S0895435610003306.

38. Balshem $H$, Helfand $M$, Schünemann $H J$, Oxman AD, Kunz R, Brozek J, et al, GRADE guidelines: 3. Rating the quality of evidence. J Clin Epidemiol. 2011; 64(4):401-6 [cited 2019 Sep 11]. Available from: https://www.sciencedirect. com/science/article/abs/pii/S089543561000332X.

39. GRADEPro GDT [Internet]. 2020. Available from: https://gradepro.org/.

40. Belzer ME, Naar-King S, Olson J, Sarr M, Thornton S, Kahana SY, et al. The use of cell phone support for non-adherent HIV-infected youth and young adults: an initial randomized and controlled intervention trial. AIDS Behav. 2014;18(4):686-96. https://doi.org/10.1007/s10461-013-0661-3.

41. Sayegh CS, MacDonell KK, Clark LF, Dowshen NL, Naar S, Olson-Kennedy J, et al. The impact of cell phone support on psychosocial outcomes for youth living with HIV nonadherent to antiretroviral therapy. AIDS Behav. 2018;22(10):3357-62. https://doi.org/10.1007/s10461-018-2192-4.

42. Bhana A, Mellins CA, Petersen I, Alicea S, Myeza N, Holst H, et al. The VUKA family program: piloting a family-based psychosocial intervention to promote health and mental health among HIV infected early adolescents in South Africa. AIDS Care - Psychol Socio-Med Asp AIDS/HIV. 2014;26(1):1-11. https://doi.org/10.1080/09540121.2013.806770.

43. Dow DE, Mmbaga BT, Turner EL, Gallis JA, Tabb ZJ, Cunningham CK, et al. Building resilience: a mental health intervention for Tanzanian youth living with HIV. AIDS Care Psychol Socio Med Asp AIDS/HIV. 2018;30(sup4):12-20. https://doi.org/10.1080/09540121.2018.1527008.

44. Dow DE, Mmbaga BT, Gallis JA, Turner EL, Gandhi M, Cunningham CK, et al. A group-based mental health intervention for young people living with HIV in Tanzania: results of a pilot individually randomized group treatment trial. BMC Public Health. 2020;20(1):1-13. https://doi.org/10.1186/s12889-020-093 80-3.

45. Donenberg GR, Cohen MH, Ingabire C, Fabri M, Emerson E, Kendall AD, et al. Applying the exploration preparation implementation sustainment (EPIS) framework to the Kigali Imbereheza project for Rwandan adolescents living with HIV. J Acquir Immune Defic Syndr. 2019;82(December):S289-98. https://doi.org/10.1097/QAl.0000000000002204.

46. Fabri $\mathrm{M}$, Ingabire $\mathrm{C}$, Cohen $\mathrm{M}$, Donenberg $\mathrm{G}$, Nsanzimana S. Correspondence: the mental health of HIV-positive adolescents. Lancet Psychiatry. 2015;2(8):e21. https://doi.org/10.1016/\$2215-0366(15)00291-6.

47. Holden S, Gordon-Dseagu VLZ, Gordon G, Chiziza N, Kiwia P, Magesa D, et al. Building resilience to adverse childhood experiences: an assessment of the effects of the stepping stones with children training programme on Tanzanian children affected by HIV and their caregivers. Health Educ J. 2019; 78(2):124-37. https://doi.org/10.1177/0017896918787217.

48. Hosek SG, Harper GW, Lemos D, Burke-Miller J, Lee S, Friedman L, et al. Project ACCEPT: evaluation of a group-based intervention to improve engagement in care for youth newly diagnosed with HIV. AIDS Behav. 2018; 22(8):2650-61. https://doi.org/10.1007/s10461-018-2034-4.

49. Jeffries C, Ross P, Matoff-Stepp S, Thompson R, Harris J, Uhrig J, et al. Ucare4life: mobile texting to improve HIV care continuum outcomes for minority youth. In: Topics in Antiviral Medicine [Internet]; 2016. p. 427. Available from: http://www.iasusa.org/sites/default/files/tam/24-e1-4.pdf\%5C n. http://ovidsp.ovid.com/ovidweb.cgi?T=JS\&PAGE=reference\&D=emed1 8b\&NEWS $=N \& A N=613268941$.
50. Letourneau E, Ellis D, Naar-King S, Chapman J, Cunningham P, Fowler S. Multisystemic therapy for poorly adherent youth with HIV: results from a pilot randomized controlled trial. AIDS Care. 2013;25(4):507-14. https://doi. org/10.1080/09540121.2012.715134.

51. Mimiaga MJ, Bogart LM, Thurston IB, Santostefano CM, Closson EF, Skeer $M R$, et al. Positive strategies to enhance problem-solving skills (STEPS): a pilot randomized, controlled trial of a multicomponent, technologyenhanced, customizable antiretroviral adherence intervention for HIVinfected adolescents and young adults. AIDS Patient Care STDs. 2019;33(1): 21-4. https://doi.org/10.1089/apc.2018.0138.

52. Naar-King S, Wright K, Parsons JT, Frey M, Templin T, Lam P, et al. Healthy choices: motivational enhancement therapy for health risk behaviors in HIVpositive youth. AIDS Educ Prev. 2006;18(1):1-11. https://doi.org/10.1521/aea p.2006.18.1.1.

53. Naar-King S, Parsons JT, Murphy DA, Chen X, Harris DR, Belzer ME. Improving health outcomes for youth living with the human immunodeficiency virus. Arch Pediatr Adolesc Med. 2009;163(12):1092-8. https://doi.org/10.1001/archpediatrics.2009.212.

54. Rongkavilit C, Naar-King S, Koken J, Bunupuradah T, Chen X, Saengcharnchai $P$, et al. A feasibility study of motivational interviewing for health risk behaviors among Thai youth living with HIV. J Assoc Nurses AIDS Care. 2014;25(1):1-7. https://doi.org/10.1016/j.jana.2012.02.008.

55. Webb L, Perry-Parrish C, Ellen J, Sibinga E. Mindfulness instruction for HIV-infected youth: a randomized controlled trial. AIDS Care Psychol Socio Med Asp AIDS/HIV. 2018;30(6):688-95. https://doi.org/10.1080/09540121.2017.1394434.

56. Whiteley L, Brown LK, Mena L, Craker L, Arnold T. Enhancing health among youth living with HIV using an iPhone game. AIDS Care Psychol Socio Medical Asp AIDS/HIV. 2018;30(sup4):21-33. https://doi.org/10.1080/09540121.2018.1503224.

57. Agwu A, Trent M. Technology based community health nursing to improve combination anti-retroviral therapy (CART) adherence and virologic suppression in youth living with HIV (Tech2Check ). ClinicalTrials. 2020; Available from: https://clinicaltrials.gov/ct2/show/NCT03600103.

58. Amico KR, Dunlap A, Dallas R, Lindsey J, Heckman B, Flynn P, et al. Triggered escalating real-time adherence intervention to promote rapid HIV viral suppression among youth living with HIV failing antiretroviral therapy: protocol for a triggered escalating real-time adherence intervention. JMIR Res Protoc. 2019;8(3):e1 1416. https://doi.org/10.2196/11416.

59. Belzer ME, MacDonell KK, Ghosh S, Naar S, McAvoy-Banerjea J, Gurung S, et al. Adaptive antiretroviral therapy adherence interventions for youth living with HIV through text message and cell phone support with and without incentives: Protocol for a sequential multiple corresponding author. JMIR Res Protoc. 2018;7(12):e11183 Available from: http://www.resea rchprotocols.org/2018/12/e11183.

60. Donenberg G, Dow D. IMPAACT 2016: evaluating a group-based intervention to improve mental health and ART adherence among youth living with HIV in low resource settings: a study of the International Maternal Pediatric Adolescent Evaluating a Group-Based Intervention. 2016. [Email communication from authors].

61. Horvath KJ, Maclehose RF, Martinka A, Dewitt J, Sullivan P, Amico KR. Connecting youth and young adults to optimize antiretroviral therapy adherence (YouTHrive): Protocol for a randomized controlled trial. JMIR Res Protoc. 2019;8(7):e11502 Available from: https://www.researchprotocols. org/2019/7/e11502/.

62. Mimiaga MJ, Kuhns LM, Biello KB, Olson J, Hoehnle S, Santostefano CM, et al. Positive STEPS: a randomized controlled efficacy trial of an adaptive intervention for strengthening adherence to antiretroviral HIV treatment among youth: study protocol. BMC Public Health. 2018;18(1):867. https://doi. org/10.1186/s12889-018-5815-9.

63. Outlaw AY, Naar-King S. Motivational enhancement system for adherence (MESA) for youth starting ART [Internet]. ClinicalTrials. Available from: https://clinicaltrials.gov/ct2/show/NCT02761746.

64. Arnold EM, Swendeman D, Harris D, Fournier J, Kozina L, Abdalian S, et al. The stepped care intervention to suppress viral load in youth living with HIV: protocol for a randomized controlled trial. J Med Internet Res. 2019; 21(2). https://doi.org/10.2196/10791.

65. Sam-Agudu NA, Pharr JR, Bruno T, Cross CL, Cornelius LJ, Okonkwo P, et al. Adolescent coordinated transition (ACT) to improve health outcomes among young people living with HIV in Nigeria: study protocol for a randomized controlled trial. Trials. 2017;18(1):595. https://doi.org/10.1186/s13 063-017-2347-z2017;1-12. 
66. Sibinga E. Mindfulness-based stress reduction (MBSR) to improve HIVinfected adolescent and young adults' HIV medication adherence and selfregulation: Protocol. 2018. [Email communication from authors].

67. Subramanian S, Edwards P, Roberts ST, Musheke M, Mbizvo M. Integrated care delivery for HIV prevention and treatment in adolescent girls and young women in Zambia: protocol for a corresponding author. JMIR Res Protoc. 2019;8(10):1-13 Available from: https://www.researchprotocols.org/2 019/10/e15314.

68. Cooper V, Clatworthy J, Whetham J, Consortium E. mHealth interventions to support self-management in HIV: a systematic review. AIDS J. 2017;11(1): 119-32. https://doi.org/10.2174/1874613601711010119.

69. Michie S, Richardson M, Abraham C, Francis J, Hardeman W, Eccles MP, et al. The behavior change technique taxonomy ( $\mathrm{v} 1)$ of 93 hierarchically clustered techniques: building an international consensus for the reporting of behavior change interventions. Ann Behav Med. 2013;46(1):81-95. https:// doi.org/10.1007/s12160-013-9486-6.

70. Aantjes CJ, Ramerman L, Bunders JFG. A systematic review of the literature on self-management interventions and discussion of their potential relevance for people living with HIV in sub-Saharan Africa [Internet]. Vol. 95, Patient education and counseling: Elsevier; 2014. p. 185-200. Available from: http://linkinghub.elsevier.com/retrieve/pii/S0738399114000421?showall=true

\section{Publisher's Note}

Springer Nature remains neutral with regard to jurisdictional claims in published maps and institutional affiliations.

Ready to submit your research? Choose BMC and benefit from:

- fast, convenient online submission

- thorough peer review by experienced researchers in your field

- rapid publication on acceptance

- support for research data, including large and complex data types

- gold Open Access which fosters wider collaboration and increased citations

- maximum visibility for your research: over $100 \mathrm{M}$ website views per year

At BMC, research is always in progress.

Learn more biomedcentral.com/submissions 